[in press, Journal of Personality and Social Psychology, April 2020]

\title{
Human status criteria: Sex differences and similarities across 14 nations
}

David M. Buss ${ }^{1 *}$, Patrick K. Durkee ${ }^{1 *}$, Todd K. Shackelford ${ }^{2}$, Brian F. Bowdle ${ }^{3}$, David P. Schmitt ${ }^{4}$, Gary L. Brase ${ }^{5}$, Jae C. Choe ${ }^{6}$, Irina Trofimova ${ }^{7}$

${ }^{1}$ Department of Psychology, The University of Texas at Austin, United States of America;

${ }^{2}$ Department of Psychology, Oakland University, United States of America;

${ }^{3}$ Department of Psychology, Grand Valley State University, United States of America;

${ }^{4}$ Centre for Culture and Evolution, Brunel University London, United Kingdom of Great Britain and Northern Ireland

${ }^{5}$ Department of Psychological Sciences, Kansas State University, United States of America; ${ }^{6}$ Department of Life Science and Division of EcoScience, Ewha Womans University, South Korea;

${ }^{7}$ Department of Psychiatry and Behavioural Neurosciences, McMaster University, Canada

*These authors share first authorship. ${ }^{1}$ Corresponding authors at: Department of Psychology, University of Texas, Austin, Texas 78712.Email addresses: dbuss@austin.utexas.edu (D.M. Buss),pdurkee@utexas.edu (P.K. Durkee). 


\begin{abstract}
Social status is a central and universal feature of our highly social species. Reproductively relevant resources, including food, territory, mating opportunities, powerful coalitional alliances, and group-provided health care, flow to those high in status and trickle only slowly to those low in status. Despite its importance and centrality to human social group living, the scientific understanding of status contains a large gap in knowledge - the precise criteria by which individuals are accorded high or low status in the eyes of their group members. It is not known whether there exist universal status criteria, nor the degree to which status criteria vary across cultures. Also unknown is whether status criteria are sex differentiated, and the degree of crosscultural variability and consistency of sex-differentiated status criteria. The current paper investigates status criteria across 14 countries $(N=2,751)$. Results provide the first systematic documentation of potentially universal and sex-differentiated status criteria. Discussion outlines important next steps in understanding the psychology of status.
\end{abstract}

Keywords: evolution, cross cultural, hierarchy, psychology, sex differences, status 


\section{Human status criteria: Sex differences and similarities across 14 nations}

"We come into this world with a nervous system that worries about rank."

- Robert Frank, from Choosing the Right Pond.

The human social landscape is not flat. Variable degrees of hierarchical organization and differential access to resources characterize every known human group. Hierarchical rank applies at all levels of human populations, pertaining to all individuals and groups within a populationto men, to women, to kin-groups within the larger group (e.g., the Kennedys, the Kardashians), to coalitions and collectives within populations (e.g., different gangs within a city or clans within a kingdom; religions, organizations), and to larger groups within the human population (e.g., ethnicities, racial groups). Social status is the subcategory of hierarchical rank in human social groups based on respect, admiration, and reputational regard (Anderson \& Kilduff, 2009; Magee \& Galinsky, 2008; Ridgeway \& Walker, 1995). A person's status is inherently a judgment by others containing both evaluative and descriptive inferences derived from a range of events, actions, possessions, communications, characteristics, alliances, allegiances, grievances, and rivalries - each charged with positive or negative valence that increases or decreases status.

Relative rank is central to many scientific disciplines. Among sociologists, class and socioeconomic status are among the most important "structural" variables (Kraus, Piff, \& Keltner, 2011). Status differentials loom large in the ethnographies of anthropologists (e.g., Chagnon, 1983; Hart \& Pilling, 1960), and articles address topics such as "the big man" (Brown, 1990) and the prestige functions of "potlaches" (Piddocke, 1969). Among economists, status striving is regarded as a universal human motive that drives much observed economic behavior 
(Frank, 1985). And for evolutionary scientists, access to key reproductive resources — such as desirable mates, formidable allies, abundant food, privileged territory, high-quality tools, and social influence - has been linked historically and cross-culturally to rank within the group, providing a selective rationale for the evolution of status-striving and status-evaluating mechanisms (Betzig, 1986; von Ruden \& Jaeggi, 2016). For psychologists, the processes and criteria by which status is assessed, accorded, and tracked must be based in psychological mechanisms.

\section{Unknowns of Human Status}

Despite the centrality of hierarchy and status to many scientific disciplines relatively little is known about the precise criteria by which humans assess and allocate status, respect, admiration, and reputational regard. Most theories of human status tend to focus on the broad dimensions along which humans allocate and attain status, such as dominance, power, benefit generation, competence, prosociality, expertise, and prestige (Anderson \& Kilduff, 2009; Chapais, 2015; Cheng, Tracy, Foulsham, Kingstone, \& Henrich, 2013; Hawley, 1999; Henrich \& Gil-White, 2001; Lukaszewski, Simmons, Anderson, \& Roney, 2016; Price, 2003; Willer, 2009). Although crucial for building a theory of status, these broad dimensions provide little guidance to the specific and diverse array of inputs that regulate human status assessment and allocation. Given the range of adaptive challenges faced across the environments in which humans evolved, a complete understanding of human social status requires the additional examination of the more substantive content-saturated status criteria - the specific acts, characteristics, interactions, and

events - that humans use to evaluate and allocate status and to track status trajectories over time.

Research has not yet documented which, if any, status criteria are species-typical and culturally universal; whether some criteria are reliably sex-differentiated across cultures; nor 
whether and how status criteria shift according to culture, ecology, group composition, life stage, relationship, or other contextual factors. The goal of this article is to provide an initial framework for detailing the criteria that humans use to evaluate and accord status, the ways in which these criteria differentially affect men and women, and to provide empirical tests in 14 cultures.

\section{Status in Evolutionary Perspective}

Status is a product of universal evaluative mechanisms that rank individuals within groups hierarchically and groups within populations hierarchically according to subjective perceptions of value, which create patterns of deference over resources (Blader \& Chen, 2014; Garfield, Hubbard, \& Hagen, 2019). The criteria of human status - the events, actions, communications, and associations that lead to increases and decreases in respect, admiration, reputation, prestige, deference, and influence - are evaluated by evolved psychological mechanisms that are adaptively-patterned, species-typical, numerous, and specific, reflecting the different adaptive problems that ancestral humans had to solve when interacting with others.

From an evolutionary perspective, hierarchies exist in part because individuals within groups benefited from avoiding costly conflict over resources by recognizing asymmetries in abilities, circumstances, and motivations that lead to differential success in conflict (van Vugt \& Tybur, 2015). In non-human animals, an individual's rank within hierarchies tends to be heavily dependent on success in agonistic encounters (Bush, Quinn, Balreira, \& Johnson, 2016; Chase \& Seitz, 2011; Holekamp \& Strauss, 2016).With the expansion of the human lineage into a greater number of niches and the development of language and complex symbol systems, the dimensions along which status were accorded became commensurately more numerous and complex (cf. Barkow, 1989; Henrich \& Gil-White, 2001). No longer was status based primarily on patterns 
deference to aggressively dominant individuals, but on patterns of deference across a broad and complex range of social interactions.

Dedicated and complex psychological machinery would need to have evolved in humans to monitor and accord status to others and to the self, and to track changes in status and status trajectories over time (Barkow, 1989; Gregg, Sedikedes, \& Pegler, 2018). The psychological mechanisms that interpret and evaluate status criteria would have imposed a powerful selection pressure over evolutionary history on the behavioral strategies of humans. Consequently, behavioral strategies should have evolved that function to embody the status criteria imposed by the evaluative mechanisms of other humans, much as mating strategies have evolved in part to embody the qualities desired in potential mates that individuals are motivated to attract. These strategies may be regulated by systems that compare one's traits and abilities in evolutionarilyrelevant domains to a cognitive map of socially valuable traits to compute feelings of self-esteem proportional to the degree one should be held in esteem by others, such as the hierometer or sociometer hypotheses suggest (e.g., Barkow, 1980; Kirkpatrick \& Ellis, 2001).

The Evolution of Status Criteria. The criteria by which individuals are accorded status are deeply rooted in human evolutionary history and highly non-arbitrary. Just as edible objects differ in food value and places differ in habitat value (Symons, 1987), people within a group differ in a myriad of fitness-relevant ways, such as mate value (Buss, 2016; Buss \& Schmitt, 1993; Symons, 1987) and coalitional value (Tooby \& Cosmides, 1988). These differences result in systematic differences in perceptions of relational value, and ultimately respect, reputation, prestige, and status. The psychological mechanisms that evaluate and determine status criteria are designed by the forces of natural selection operating over thousands or millions of years. Therefore, the criteria that humans use to allocate and evaluate status will ultimately be 
determined by factors that would have influenced the survival and reproductive success of our ancestors. Just as humans evolved separate taste preferences for sugar, fat, salt, and protein to solve different nutritional requirements, we expect that humans have evolved mechanisms to evaluate status criteria that correspond to the different adaptive challenges and fitness consequences posed by interacting with others. Because of the multitude of ways in which other individuals can affect our survival and reproductive success, the psychological mechanisms that have evolved to evaluate and accord status to others are likely to be numerous and specific (cf. Symons, 1987).

Hypotheses about the evolution of specific status criteria in humans require consideration of the selection pressures recurring across human ancestral environments. Although creating a plausible model of the human environment of evolutionary adaptedness (EEA) is fraught with difficulties (DeVore \& Tooby, 1987), researchers and theoreticians have converged on several basic points of reasonable consensus. Through converging information from the paleontological record, the archaeological record, our knowledge of ancient habitats, our knowledge of patterns of primate homology, the characteristics present in contemporary small-scale societies (e.g., hunter-gatherers, pastoralists, horticulturalists), and characteristics present in modern humans, we can piece together a plausible scenario of some key aspects of human ancestral conditions (see DeVore \& Tooby, 1987).

Ancestral environments. Throughout human evolution, males had lower obligatory parental investment than females. Females bore the energetic and time costs of gestation and months or years of breastfeeding, whereas a male's minimum investment was only the contribution of sperm required for successful fertilization (Trivers, 1972). Over evolutionary time, this asymmetry would have driven women to be more selective about whom to mate with 
relative to men, at least in some mating contexts (Buss, 2016). Men would have had to compete comparatively more for sexual access.

Evidence overwhelmingly suggests that hunting and gathering were major human activities across human evolutionary history (DeVore \& Tooby, 1987; Hill, 1982; Liebenberg, 2008). Ancient humans ate a variety of foods, but calories from meat tend to be more nutrientdense than calories from plants, so meat would have been valuable food. The time constraints of breastfeeding combined with the impracticality of caring for an infant throughout protracted hunting expeditions suggests that ancestral women probably spent more time gathering and processing sessile foods than chasing game. Hunting, especially large-game hunting, was practiced primarily by coalitions of men.

Hunting makes it possible to obtain large, calorically-dense packets of meat-more than the amount any one hunter needed or could reasonably consume. But hunting returns are highly variable across cultures (Hawkes \& Jones, 1991; Kaplan \& Hill, 1985; Kaplan, Gurven, Hill, \& Hurtado, 2005). The interaction between large payoffs and high variability created conditions that elevated levels of food-sharing to a degree not seen in other primate species and promoted the evolution of psychological mechanisms for social exchange (Cosmides \& Tooby, 2016; Stanford, 1999); early cultural norms likely arose from these mechanisms. The benefits of living in larger groups - and the increasing costs of ostracism (e.g., starvation, predation)—would have created additional selection pressures honing adaptations for group living (e.g., reputation management; Stibbard-Hawkes, 2019).

Hunting - especially large-game hunting — also required higher levels of cooperation among males, creating selection pressures to form coalitions and psychological mechanisms attendant to coalitions (Tooby \& Cosmides, 1988; Tooby \& Cosmides, 2010). The existence of 
coalitions created further opportunities for acquiring resources (e.g., territory, food, mates) through inter-coalitional aggression, which created selection pressures for coalitional defense (Alexander, 1987). There is compelling evidence for the hypothesis that men formed cooperative coalitions for the purposes of large-game hunting, coalitional aggression (sometimes to capture wives), and coalitional defense against aggressive male coalitions (e.g., Alexander, 1987; Chagnon, 1983; Pandit, Pradhan, Balashov, \& Van Schaik, 2016). There is no evidence that women in ancestral environments formed coalitions with other women to raid neighboring tribes to capture husbands or to hunt large-game animals (Tooby \& Cosmides, 1989), although women likely formed alloparenting networks (Hrdy, 2009; Shostak, 1981). Intergroup conflict and warfare likely exerted strong selection pressures on men across human evolutionary history (Manson \& Wrangham, 1991; Tooby \& Cosmides, 1988; van Vugt, Cremer, \& Janssen, 2007). Calorically dense food packets from hunting created the possibility for heightened average levels of male parental investment, exceeding that of other primates. Women who could reliably access high-calorie nourishment for themselves and their offspring would have had higher reproductive success than women who could not. Thus, the genes of women who secured investing mates, as well as those of men who invested, would have been better represented in subsequent generations - leading to higher male investment over time. The combination of higher male parental investment and relatively concealed ovulation in women selected for men who placed greater importance on assuring their paternity in offspring of long-term mates. The interaction between long-term mating strategies and relatively high male parental investment created selection pressures on men to select mates of high long-term reproductive value (i.e., young, healthy, nulliparous women; Sugiyama, 2015; Symons, 1979). Tradeoffs between short- 
term and long-term mating led to the evolution of short-term and long-term sexual strategies (Buss \& Schmitt, 1993, 2019).

Sketches of some of the important and relatively invariant features of ancestral environments provide a crudely formulated context for advancing general hypotheses about the status criteria that humans use to evaluate each other. Sex differences in reproductive biology and investment selected for sex differences in psychology and behavior, which led to sexual divisions of subsistence labor in our hunter-gatherer ancestors (Broude, 1990). These ancestral divisions of labor fostered sexually asymmetric cultural values and expectations whereby different traits and affordances became differentially valuable in and to men and women, creating a feedback loop between culture and our evolved psychology; culture and evolved psychology co-evolved. Sex differences in value that emerged across a range of relationship domains - from mate value to kin value — would have been maintained by individual expectations and cultural norms, ultimately manifesting in differences in the criteria of status. A diagrammatic depiction of our model of the evolution of human status criteria is shown in Figure 1. 


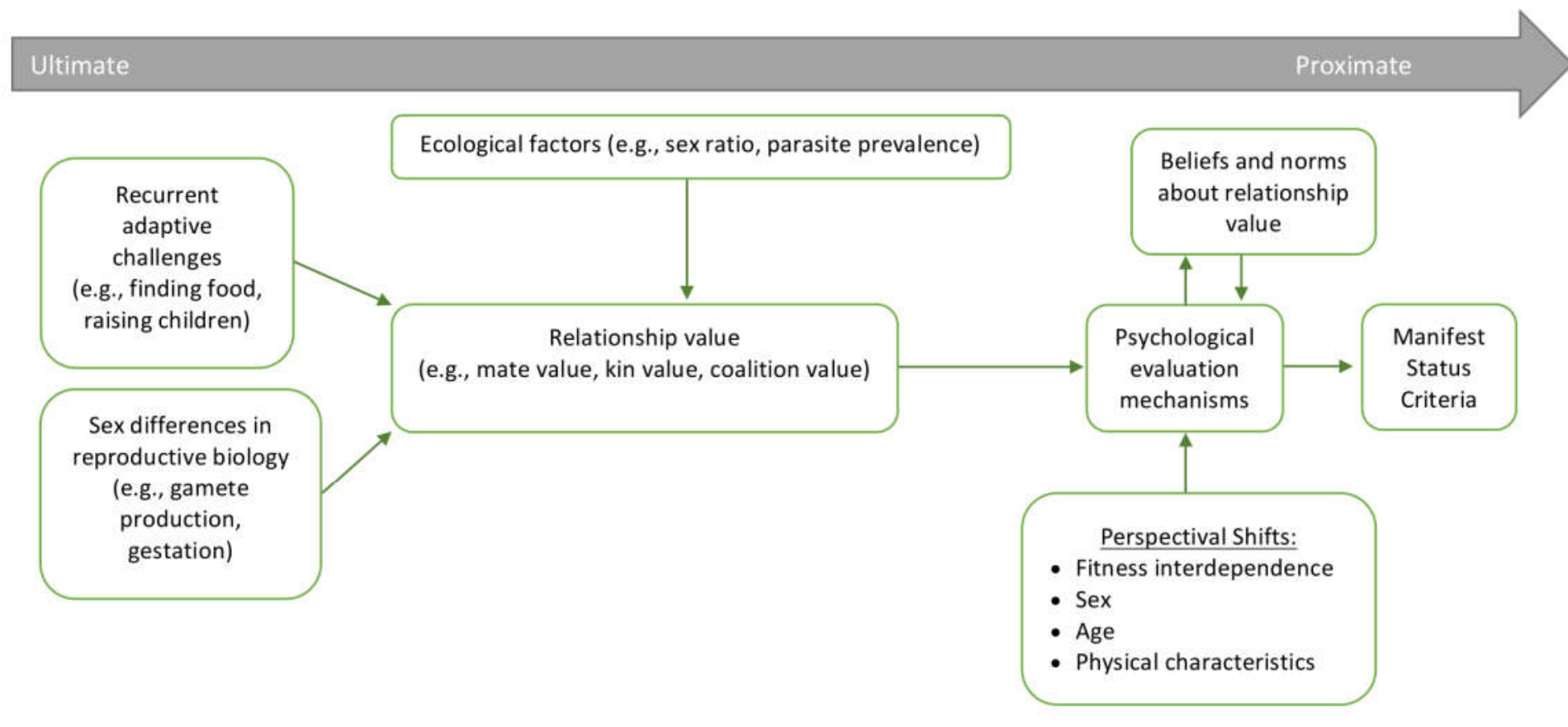

Figure 1. Model of the evolution of human status criteria from ultimate to proximal causes of manifest criteria. 


\section{General Hypotheses about Status Criteria}

The status criteria linked with each of the different major forms of human relationships, shown in Table 1, are expected to be partially overlapping and partially distinctive. The mate value of a woman, for example, can be an asset to potential mates, as well as to her kin groupparticularly in cultures in which marriage is arranged by kin and women are exchanged between groups (e.g., Apostolou, 2007). The higher a woman's mate value, the higher her value to kin in forming political alliances and in obtaining desirable wives and other resources in exchange (e.g., Apostolou, 2013; Hart \& Pilling, 1960). Analogously, a man's athletic prowess and hunting ability can increase his value as a coalition member, as a kin member, as a reciprocal ally, and as a mate (Hill \& Hurtado, 1996; Gurven \& von Rueden, 2006; Patton, 2005).

Table 1.

Abstract classes of relational value and conceptual definitions.

\begin{tabular}{ll}
\hline Classes of Relational Value & Conceptual Definition \\
\hline Kin Value & Value to immediate and extended family. \\
Coalitional Value & $\begin{array}{l}\text { Value to specific coalitions, collective action, } \\
\text { hunting and war parties. }\end{array}$ \\
Mate Value & Value to one's mate and prospective mates. \\
Reciprocal Exchange Value & Value as partner across one-shot and repeated dyadic \\
& interactions (e.g., trading, alliance).
\end{tabular}

The utility of differentiating the different classes of value is not that these classes are entirely independent (they are not), but rather that some criteria differentially affect one's value within each of these major forms of human relationships. We may tolerate lack of reciprocation from kin, for example, but refuse to tolerate it in a non-kin dyadic alliance. We may value strength or bravery more strongly in a coalitional partner than a reciprocal exchange partner, or 
value agreeableness more in an exchange partner than coalition member. To take another example, a substantial cost may be incurred if one's mate has an extramarital affair, but not if a friend has an extramarital affair (unless it is with one's mate).

Costs and benefits differ depending on the nature of the relationships. It is plausible to hypothesize that distinct psychological mechanisms have evolved for each of these relationships to the degree that the constituents of value differ for each, the costs carried by relationship violations differ for each, and hence the adaptive problems one must solve to extract the relevant value differ for each (cf., Tooby \& Cosmides, 1988). Thus, we expect some degree of overlap in the status criteria between relationship domains. We delineate hypotheses and predictions that apply equally to women and men and those that differ between the sexes.

Status criteria central to both sexes. Given the multitude of adaptive problems that are the same for men and women, we expect that many of the criteria that humans use to assess and allocate social status will not be sex-differentiated (Figure 2).

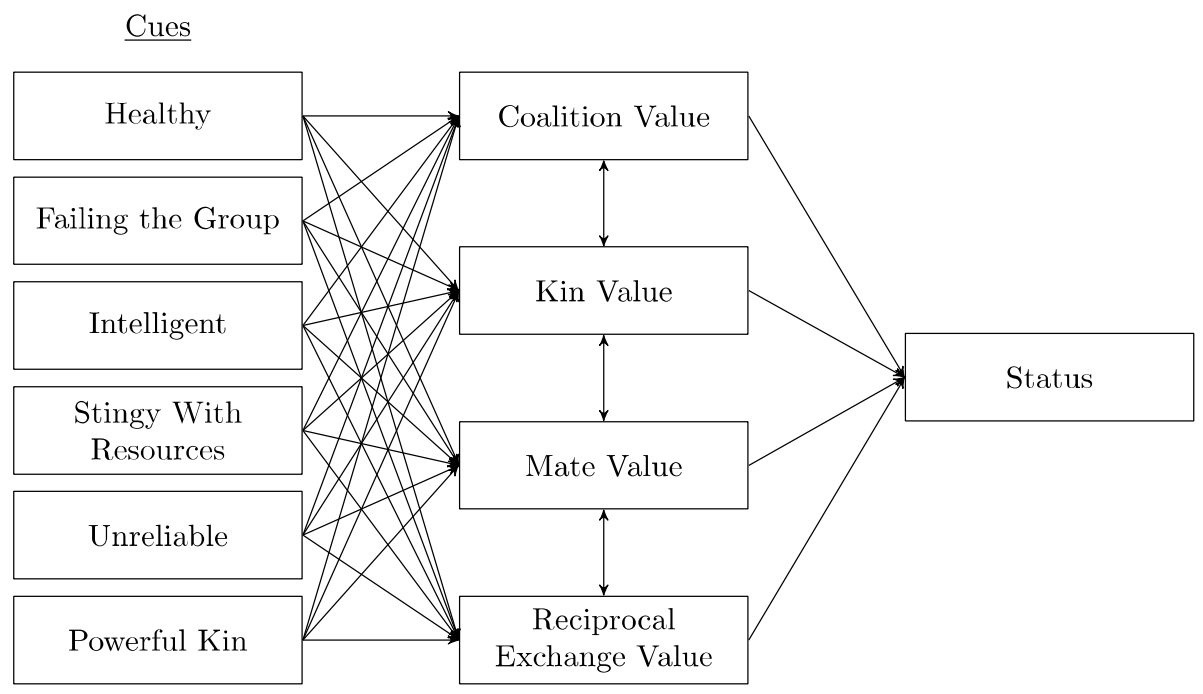

Figure 2. Model depicting examples of cues central to the relational value of both men and women across domains that ultimately result in universal status criteria. 
Health would have been central to the social value of men and women across all fitnessrelevant domains (Sugiyama, 2015); thus, we hypothesize that overall health will be equally important for both women and men. We also hypothesize that many components of kin-support, as well as general aspects of group value and social exchange value, will not be sexdifferentiated because many aspects of value in each domain are not sex-differentiated. Specifically, we predict that criteria related to kin-alliances will be central to both men and women because kin would have tended to be the strongest allies and would have provided a consistent pool of shared resources to draw from. Having high-status and supportive kin members would have been beneficial for both men and women for raising social-exchange value. Being a valuable member across domains (e.g., being trusted, willingness to share resources) should be central to both men's and women's status because others would be more willing to reciprocate or initiate fitness-enhancing social exchanges. Thus, we expect that many aspects of group and social value would not be sex-differentiated. We also do not expect direct reproductive output, such as having children, to have different impacts on the status of men and women.

Sex-differentiated status criteria. Sex differences are only expected to occur within the delimited domains in which women and men have recurrently faced different adaptive problems over human evolutionary history (Buss, 1995). In contrast, where they have faced similar adaptive problems, psychological similarity is expected. We hypothesize that status criteria will differentially impact men and women in domains where there are sex differences in the perceived components of relational value. Examples of cues that are hypothesized to impact the relational value and consequent status of men and women differently shown in Figures 3 and 4, respectively. 


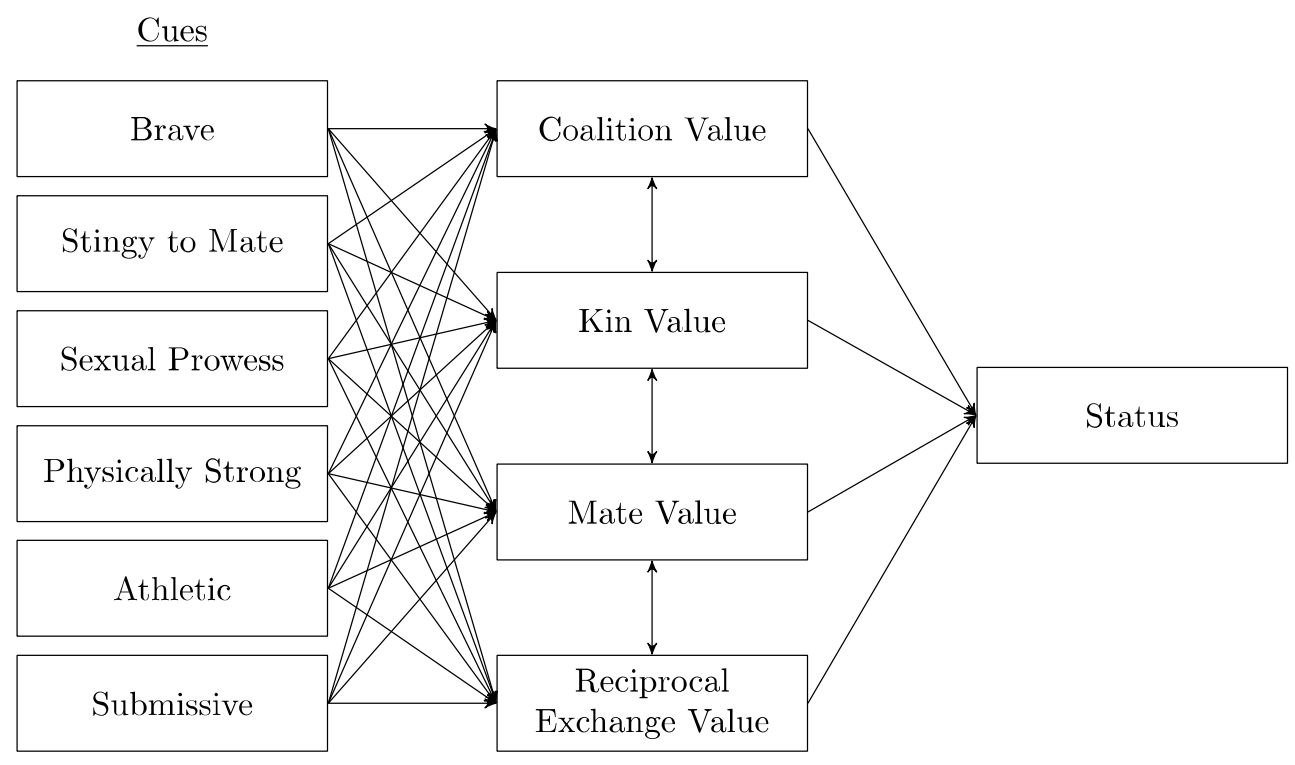

Figure 3. Examples of cues that are expected to be more central to the relational value and status of men.

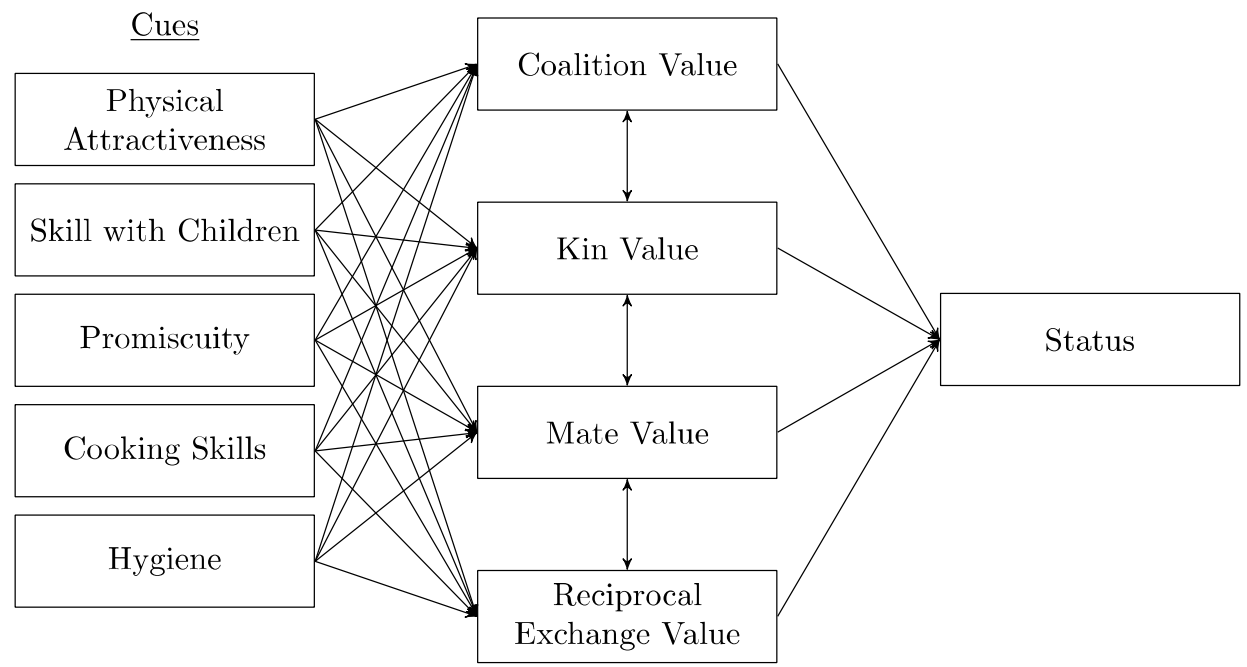

Figure 4. Examples of cues that are expected to be more central to the relational value and status of women. 
Status criteria central to men. Given that men participated in coalitional hunting and raiding at higher rates than women throughout human evolution, we hypothesize that components of value relevant to the success of hunting and warfare coalitions will be more central to the status of men than women. The success of male coalitions would have depended, in part, on their ability to coordinate actions in the pursuit of collective goals; thus, we expect that leadership qualities will be more central to men's status than women's. This is not the same as claiming that leadership abilities will not enhance women's status, but rather that leadership abilities will be more crucial for men's status than women's, on average. Another major component of coalitional success is the ability and willingness of its members to achieve shared goals (e.g., tracking and killing an animal, defeating a rival group). This would depend heavily on men's athleticism, physical formidability, bravery, and likelihood of defection, so we expect men's status to hinge more heavily on these criteria than women's status. Many of these traits would also have been relevant to a man's ability and willingness to protect their mates and offspring, which strengthens our expectation that these components of status criteria will be more central to men than women. Because resource acquisition ability would have been a critical component of men's mate value, we also expect that components of the ability to provide resources (e.g., hunting ability) will be more central to men's status than women's status. This does not imply that ability to acquire resources will not be important to women's status (it should), but rather that it will be more important to men's than to women's status.

Status criteria central to women. For reasons outlined previously, ancestral women would have been responsible for most domestic duties (e.g., processing food, childcare). Thus, we hypothesize that women's status will depend more on domestic skills than will men's status. This prediction may obtain more strongly in traditional societies. Cultural shifts toward 
egalitarian domestic duty sharing in many Western cultures may diminish or even eliminate these sex differences in more modern countries. We also hypothesize that physical attractiveness will be more central to women's status than men's due to the greater weight physical attractiveness has played in women's mate value over evolutionary time, particularly in longterm mating contexts (Buss, 1989; Buss \& Schmitt, 2019). A woman's attractiveness would have impacted her ability to access high-resource mates and, consequently, her relational value to kin and social partners.

Mating strategy and status criteria. High status - obtained by embodying the criteria imposed by others - enables an individual to carry out his or her preferred sexual strategy, whereas low status inhibits an individual's ability to carry out his or her preferred sexual strategy. For men, this tends to mean better odds of obtaining — or failing to obtain — long-term mates of high desirability (e.g., youthful, physically attractive, not promiscuous), as well as access to multiple mates or short-term opportunistic copulations. For women, this tends to mean better odds of obtaining — or failing to obtain — a long-term mate or marriage partner who invests heavily (e.g., commitment, parental investment), a marriage partner of high mate desirability (e.g., one with resources), and under some circumstances, being able to attract short-term sexual liaisons and access the resources and possibly genes of high status men. Here we test the prediction that carrying out one's preferred sex-typical sexual strategy will be associated with higher status, whereas being unable to carry out the preferred sexual strategy will be associated with lower status (see Figure 5). Thus, we hypothesize that criteria central to men's sexual strategy (e.g., having a young, fertile mate) will have greater impacts on the status of men than women, and that criteria central to women's sexual strategy (e.g., securing high-resource mates) will impact women's status more than men's status. 


\section{The Current Study}

No systematic analysis has detailed the relative impacts that various personal characteristics have on status and reputational regard across cultures. No studies explicitly test which actions, events, qualities, and associations reliably affect the status of men and women differently across cultures. There remains a gap in the scientific understanding of status - the precise qualities, actions, and events that humans use to evaluate the status of other individuals. To fill this lacuna, we employ ratings of the status impacts of 240 specific events, characteristics, and behaviors, and from 14 countries, from Brazil to Zimbabwe, to explore and document human status criteria, and we test basic predictions based on hypotheses drawn from evolutionary metatheory about sex differences and sex similarities in human status criteria.

To summarize, we hypothesize that (1) men's and women's status criteria will depend equally on skills and characteristics that increased their relational value equally across domains throughout our evolutionary history and (2) that that there will be sex differences in status criteria where ancestral relational value differed between the sexes. Regarding status criteria central to both men and women, we predict that health, characteristics related to general group and social exchange value, having children, and kin alliances, will not have sex-differentiated status impacts. Regarding sex differences, we predict that men's status will be more dependent on characteristics relating to willingness and ability to protect, athleticism, leadership qualities, and resource acquisition abilities, whereas women's status will be more dependent on characteristics relating to reproductive value (e.g., attractiveness) and domestic skills. Importantly, we predict that sex-differentiated aspects of men's and women's sexual strategies will also have sex-differentiated status impacts. 


\section{Method}

\section{Participants}

A total of 2,751 (1,487 women) people from 14 countries across five continents participated in this research. The sex-specific sample size and average participant age for each country is presented in Table 2 .

Table 2.

International Sample Sizes and Ages.

\begin{tabular}{|c|c|c|c|c|c|c|c|}
\hline \multirow[b]{2}{*}{ Sample } & \multicolumn{3}{|c|}{ Sample Size } & \multicolumn{2}{|c|}{ Age of Men } & \multicolumn{2}{|c|}{ Age of Women } \\
\hline & Men & Women & Total & $M$ & $S D$ & $M$ & $S D$ \\
\hline Brazil & 100 & 100 & 200 & 27.24 & 10.79 & 24.40 & 8.98 \\
\hline China & 113 & 93 & 206 & NA & NA & NA & NA \\
\hline Colombia & 100 & 100 & 200 & 21.14 & 4.13 & 19.80 & 2.15 \\
\hline Eritrea & 118 & 64 & 182 & 21.41 & 2.97 & 19.85 & 1.65 \\
\hline Estonia & 46 & 92 & 138 & 21.96 & 5.22 & 22.00 & 5.08 \\
\hline Germany & 83 & 148 & 231 & 23.84 & 4.92 & 24.11 & 5.68 \\
\hline Guam & 35 & 70 & 105 & 20.74 & 6.06 & 19.99 & 4.26 \\
\hline Japan & 100 & 100 & 200 & 19.18 & 1.01 & 20.03 & 1.35 \\
\hline Korea & 100 & 102 & 202 & 22.86 & 3.23 & 22.64 & 3.40 \\
\hline Poland & 48 & 36 & 84 & 23.04 & 1.75 & 22.17 & 1.89 \\
\hline Romania & 55 & 42 & 97 & 34.53 & 11.22 & 30.86 & 13.72 \\
\hline Russia & 100 & 100 & 200 & NA & NA & NA & NA \\
\hline USA & 143 & 362 & 505 & 22.16 & 5.43 & 24.27 & 6.74 \\
\hline Zimbabwe & 123 & 78 & 201 & 20.61 & 3.19 & 20.38 & 2.68 \\
\hline Total Sample & 1264 & 1487 & 2751 & 23.23 & 4.99 & 22.54 & 4.80 \\
\hline
\end{tabular}

Note. NA = age data were not collected in this sample. The Romania sample is a convenience sample of Romanian Gypsies in Roma. 


\section{Materials and Procedures}

Generation of status-affecting items. The status-affecting items - the acts, characteristics, and events that raise or lower status - were generated through a mix of actnomination procedures and expert input. Early in the item generation process, one sample of American undergraduates nominated actions, characteristics, and events that could increase status and reputation, while a second sample nominated actions, characteristics, and events that could decrease status and reputation. We culled the nominations, eliminating redundancies, grammatical errors, and vague statements, but erred on the side of over-inclusion, retaining all acts and events that had even partial distinctiveness. This process resulted in 175 status-affecting items.

Additional items were added stochastically over time as a result of discussions with anthropologists and psychologists who had specific knowledge of different cultures. For example, our Chinese collaborator suggested that having a male child may increase status in China more than having a female child, so two items were added to reflect this nuance. Additional items were added to test the specific hypotheses outlined above. For example, "showing bravery in the face of danger" was added to test the hypothesis about sex-linked status criteria as a function of the different forms of male and female coalitions. Researchers who collected cross-national data added additional items over time. In total, this generation process resulted in 240 status-affecting actions, characteristics, and events.

We make no claims that this list is exhaustive. In principle, thousands of acts, events, characteristics, and interactions have consequences for increasing or decreasing an individual's status. Moreover, some status criteria will be specific to novel forms of modern culture, which change constantly. For example, skill at computer coding or data visualization could not have 
been status criteria among human ancestors, but among some modern subcultures these skills are highly valued. Consequently, no list of status criteria will be exhaustive or complete. Rather, this study provides an initial foray into the large gap in understanding what causes people's status to rise or fall. It also provides initial cross-cultural tests of hypotheses about universal and sexdifferentiated status criteria.

Status-impact ratings. Respondents across the 14 countries rated the distinct impact of the full list items available at the time of data collection ${ }^{1}$ according to the prompt:

"In this study, we are interested in the effects of certain events and behaviors on the status and reputation of the persons who perform these acts or experience these events. Some will be likely to increase a person's status and reputation in the eyes of their peer group; others will be likely to decrease their status and reputation in the eyes of their peer group. Please use the scale below (ranging from +4 to -4 ) to rate the likely effects of each act or event on status and reputation (1) for males (event happens to or is performed by a man) and (2) for females (event happens to or is performed by a woman). For some events and behaviors, the effects on status and reputation may be the same for men and women; for others, the effects on status and reputation may be different for men and women." Respondents rated each item twice- once in reference to the impact on men, and once in reference to the impact on women. Researchers who collected data within each country translated the prompt and items into the language most relevant to their culture or country using a three-step process. First, a bilingual speaker translated the items into the relevant language. Then, a second bilingual speaker translated the items back into English. Finally, a third bilingual

\footnotetext{
${ }^{1}$ Because the list of status-affecting items was added to over time, the number of items available for participants in each country to rate also changed. Due to a researcher miscommunication, Eritrean participants only assessed the status criteria pertaining to their own sex.
} 
speaker resolved any discrepancies between the original wording and the back-translation. The full instructions sent to cross-national collaborators are provided in the online supplemental materials (https://osf.io/2av76/?view_only=923683921b6547db81089987be64438b).

Astute readers may notice that the rating prompt is somewhat double-barreled because it asked raters to think about the "effect on status and reputation." Theoretically, these constructs are expected to overlap to a large degree, but they are partially distinct. It is possible that this conflation could qualitatively affect our results. Given that this archival dataset was collected over a decade ago, we could not directly address this issue. We did, however, attempt to investigate the likelihood that the double-barreled prompt led to qualitatively different results than ratings of only status or only reputation.

We asked separate groups of American raters to rate all 240 status-affecting items using the same prompt as in the international data collection, but we altered to prompt throughout to say either only "effects on status" $(n=41)$ or only "effects on reputation" $(n=34)$. These more specific ratings exhibited high interrater agreement (ICCs ranged from .76 - .92). Moreover, they were very highly intercorrelated for both male and female targets $\left(M_{r}=.84\right.$, range $\left.=.80-.92\right)$, as well as with the ratings from every country based on the original prompt $\left(M_{r}=.85\right.$, range $=$ $.73-.95)$. The full correlation matrix between status-only ratings, reputation-only ratings, and international ratings based on the original prompt is provided in the online supplementary materials (https://osf.io/2av76/?view_only=923683921b6547db81089987be64438b). The high correlations between ratings based on different prompts suggest that results based on ratings from the original prompt are unlikely to be qualitatively_or even statistically_different had it specified only status or only reputation. 
Item clustering. We directed four trained research assistants to group the status-affecting items according to shared content, which we labelled accordingly (content clusters). We then further grouped these content-clusters into theoretically-relevant domains (domain clusters) according to our hypotheses. Groupings were set before analyses were conducted. Some of the status-affecting items did not fit neatly into our hypotheses (e.g., aspects of personality, drug use), so we grouped them separately for use in exploratory analyses. In cases in which the items potentially overlapped across domain or content clusters, we opted to keep categories separate rather than to merge them to preserve unique information. Discrepancies in grouping decisions were resolved through discussion. A table showing the placement of all 240 items within clusters and domains is presented in the supplemental materials.

\section{Analytic strategy}

We examined the magnitudes of sex differences in status criteria across three levels of analysis: item level, content level, and domain level. The item level assessed sex differences at the level of specific items (e.g., "being brave in the face of danger", "being bold"; "being physically strong”, "being a good fighter"). The content level meta-analyzed the item-level sex differences within content clusters (e.g., bravery, formidability). Finally, the domain-level analyses meta-analyzed the item-level sex differences according to domain clusters (e.g., Ability and Willingness to Protect). We describe the details of how we sought to maximize power in our analytic strategy below.

Item level analyses. To examine the overall effect of referent-sex on the status impacts on each of the 240 acts, events, or characteristics across the 14 countries, we used the lme 4 package in R (Bates, Maechler, Bolker, \& Walker, 2015; R Core Team, 2013) to conduct multilevel regression analyses that accounted for the nested structure of the data (i.e., ratings 
nested within participants who are nested within countries) by allowing random intercepts for both participants and countries, and random slopes for countries, while controlling for raters' reported gender. In addition to Bonferroni-correcting each $p$-value for alpha inflation from 240 tests, we also adopted a critical alpha level of .005 (c.f., Benjamin et al., 2018). After adopting this extremely conservative significance threshold, we still had $80 \%$ power to detect statistically significant effects for even practically trivial differences because of our large sample size and within-subjects design. We therefore computed classical Cohen's $d$ for each effect—which is desirable because it is design-blind and comparable across designs (Morris \& DeShon, 2002)and relied on conventional cutoffs to evaluate the practical significance of effects.

Content and domain level meta-analyses. After computing item-level effects, we metaanalyzed sex differences across the pre-specified content and domain clusters. To do so, we grouped effects according to content (e.g., cleanliness, cooking ability) and theoretical domain (e.g., Domestic Skills). We then reverse-coded effects where warranted so that effects within a content-cluster were directionally consistent (e.g., "being a bad cook" was reverse-coded to directionally match the other item in the cooking ability cluster, "being a good cook"). We subsequently weighted each effect by its respective sample size and number of countries sampled and averaged the sex differences within each content and domain cluster. These aggregated content and domain clusters provide more powerful, robust, and reliable tests of our hypotheses because (1) they assess differences across the broader conceptual and theoretical domain that each item samples, and (2) the observed sex differences are less dependent on the specifics of item phrasing and item-specific sample sizes. 


\section{Results}

\section{Item-Level Overview}

Of the 240 items rated by participants across the 14 nations, 123 were judged to increase a person's status among their peers and 117 were judged to decrease status. Figure 5 presents an overview of the item-level tests of sex differences in status criteria. Most were expected a priori and fell within the small to medium effect size range (i.e., Cohen's $d$ between .2 and .5). Most of the items that exhibited trivial differences $(d<.2)$ were either expected not to differ a priori or were exploratory. The means and standard deviations of the 15 most beneficial and detrimental status-affecting items for men and women combined are presented in Table 3.

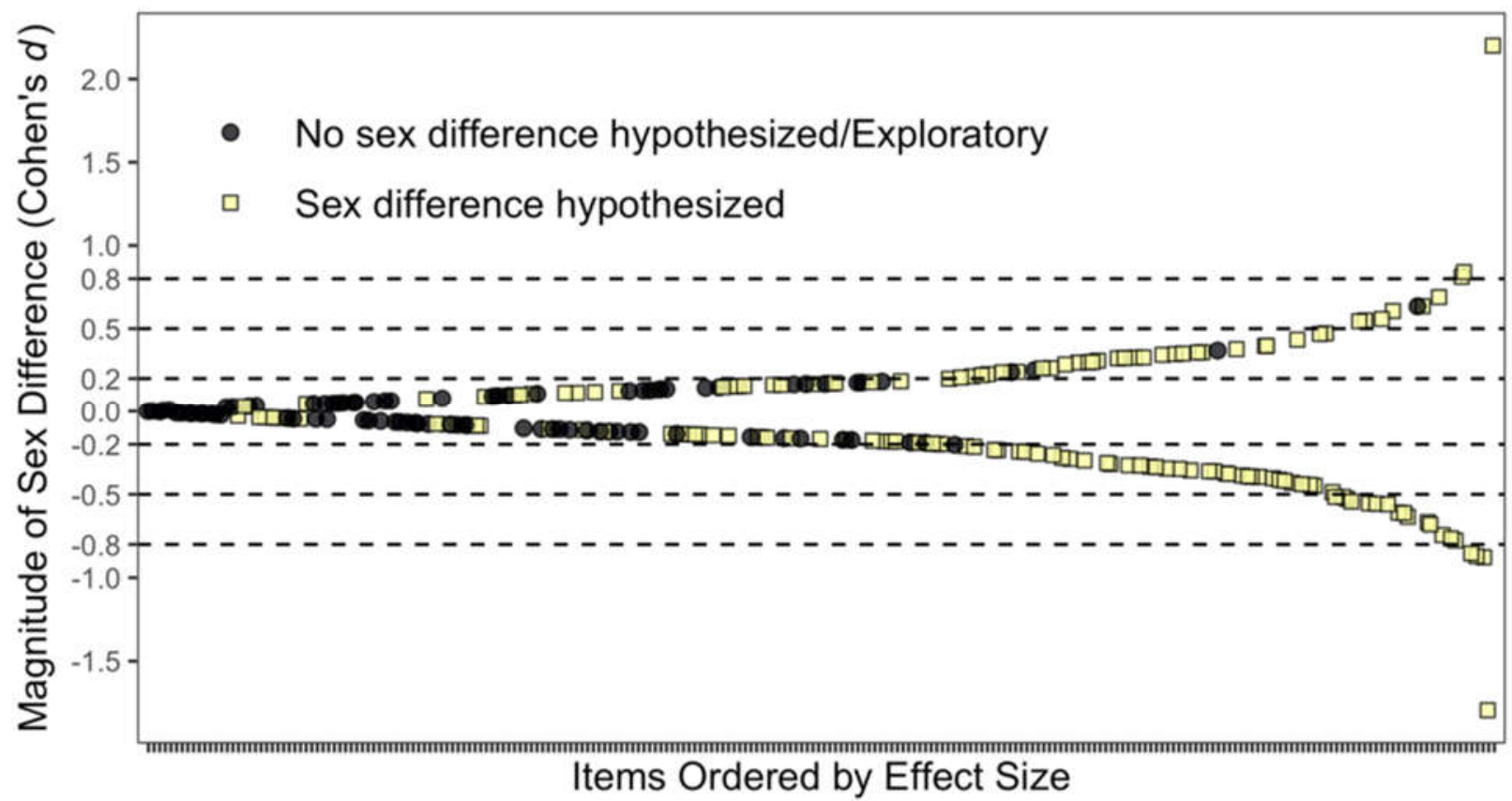

Figure 5. Distribution of item-level effect sizes (Cohen's $d$ ) arranged from smallest to largest. The dark-shaded circles represent items that were hypothesized be sex-differentiated, and the light-shaded squares represent items that were not hypothesized to differ or were exploratory. Dotted lines represent conventional cutoffs for small $(d=.2)$, medium $(d=.5)$, and large effects $(d=.8)$. Cohen's $d$ values greater than zero favor women and values less than zero favor men. 
Table 3.

The 15 most status-increasing and 15 most status-decreasing criteria for men and women combined across countries.

\begin{tabular}{llc} 
& \multicolumn{2}{c}{ Status Impact } \\
\cline { 2 - 2 } Status-affecting item & $M$ & $S D$ \\
\hline
\end{tabular}

\section{Most Status-Increasing Criteria}

Being a trusted group member

Being intelligent

Getting accepted at a prestigious university

Being an exceptional leader

2.80

1.48

Having a wide range of knowledge

2.80

1.25

Being creative

2.71

1.33

Always being honest

2.68

1.52

Being able to speak well in public

2.65

1.36

Having a job that pays well

2.64

1.39

Having a good sense of humor

2.64

1.38

Having an executive position

2.62

1.53

Being kind

2.59

1.33

Being brave in the face of danger

2.56

1.44

Having a college education

2.55

1.53

Being a hard worker

2.53

1.50

\section{Most Status-Decreasing Criteria}

Failing to perform group task

Getting dismissed from school

$-2.28$

Being lazy

$-2.29$

1.58

Being unable to control one's sexual behavior when drunk

$-2.36$

1.93

Being unreliable

$-2.42$

1.77

Acting immature or irresponsible

$-2.51$

1.47

Being mean or nasty to others

$-2.53$

1.64

Expressed racist remarks

$-2.61$

1.68

Bringing social shame on one's family

$-2.61$

1.40

Having bad manners

$-2.62$

1.50

Takes illegal drugs

$-2.66$

1.74

Getting a sexually-transmitted disease

$-2.70$

Being stupid

$-2.71$

1.47

Being unclean or dirty

$-2.96$

Being known as a thief

$-3.30$

1.34

In the interest of efficiency and economy of presentation, we now focus on the content and domain levels of analysis for primary tests of our hypotheses, highlighting interesting 
nuances in the item-level results where relevant. The complete results and plots of the 240 itemlevel analyses are provided in the supplemental materials.

\section{Status Criteria Central to Both Men and Women}

Domain level. We hypothesized that the domains of health, general group and social value, having children, and kin alliances, would be equally important to the status of both men and women (i.e., not sex-differentiated). These hypotheses were supported; the meta-analyzed sex differences are trivial across the domain clusters health, general group and social value, having children, and kin alliances (see Figure 6).

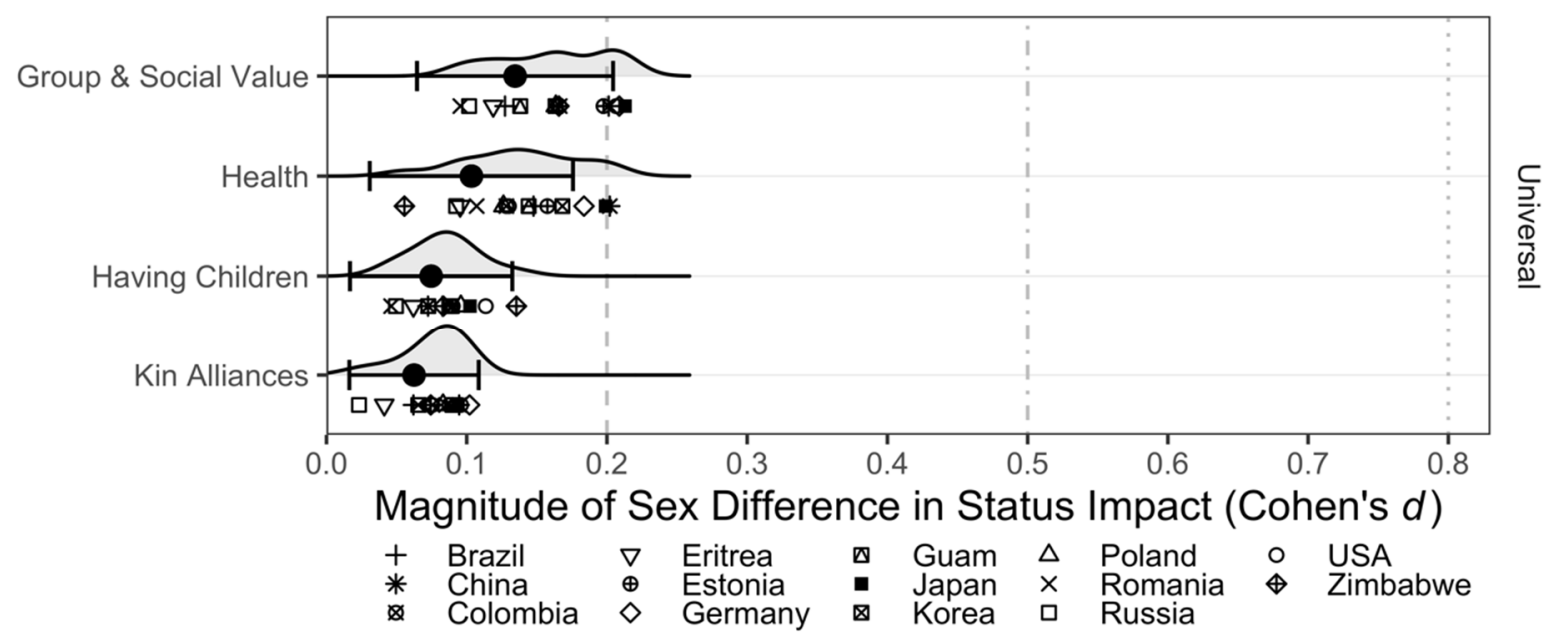

Figure 6. Meta-analyzed sex differences within domain clusters that were hypothesized to be central to the status of both men and women. Dotted lines represent conventional effect size cutoffs. Error bars represent $95 \%$ confidence intervals.

Content level. Even at the content-cluster level, nearly all sex differences across the domains of having children, group and social value, health, and kin alliances were trivial (see Figure 7). The two exceptions were small male-favoring sex differences in (1) the insult retaliation cluster, containing items addressing retaliation for public insults (e.g., "defending oneself after being slapped in the face"), and (2) the relationship differential cluster, containing 
items related to standing within interpersonal relationships (e.g., "having the upper hand in a relationship").

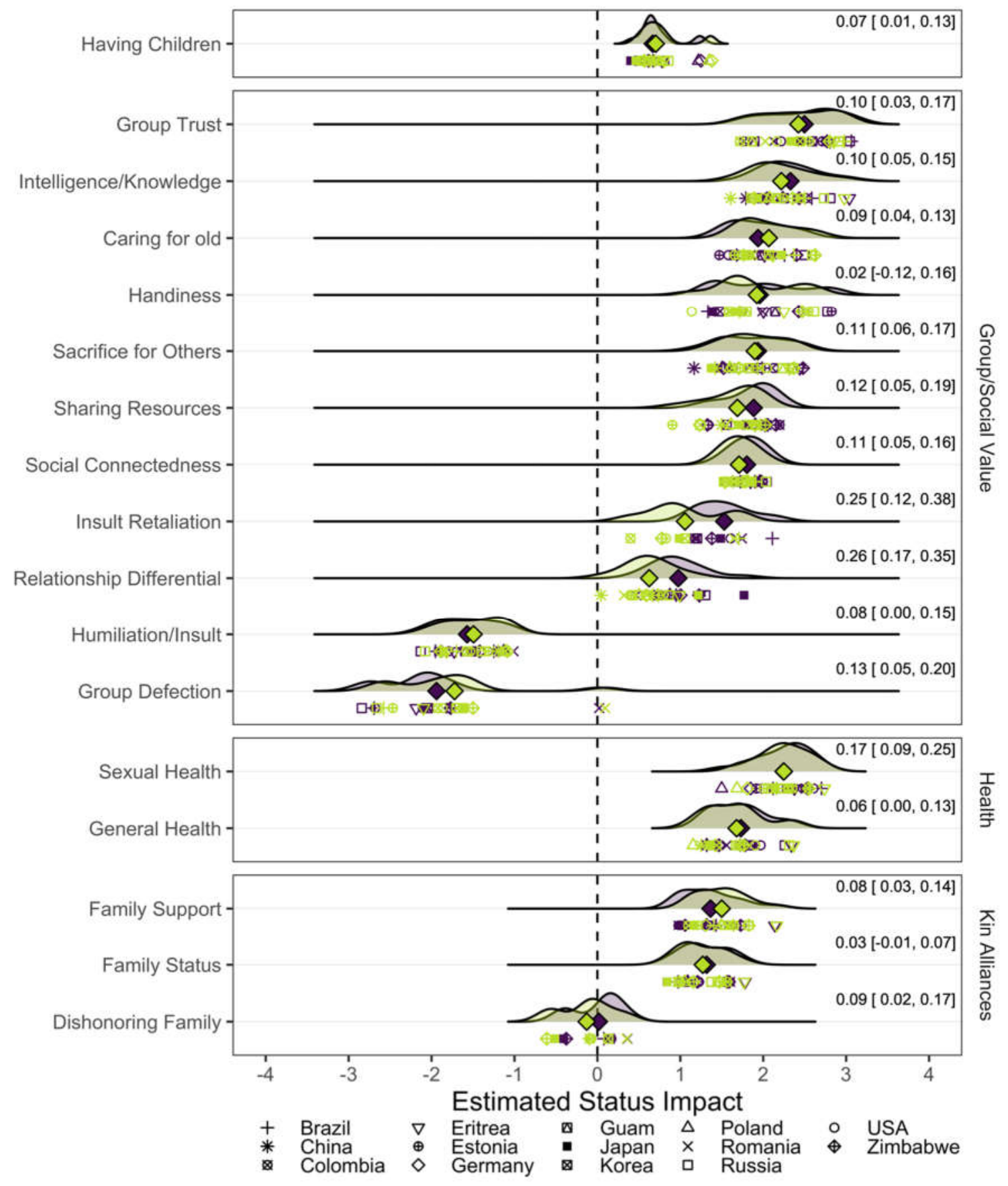

$\checkmark \operatorname{Man} \nabla$ Woman

Figure 7. Plot of universal status criteria, organized by domain-cluster, depicting the average relative status impact of a given content-specific act, characteristic, or event on men's and women's status, as well as the absolute magnitude of the sex difference (Cohen's $d$ and 95\% confidence intervals). 
In summary, many status criteria are not sex-differentiated and appear to have similar effects across nations sampled in our study, suggesting possible universality. Acts, characteristics, and events that are associated with general value to the group and to individuals within the group, value to one's kin, and physical health are three candidates for universal status criteria.

\section{Status Criteria More Central to Men}

Domain level. We predicted that clusters relevant to the domains of leadership, ability and willingness to protect others, resource acquisition, athleticism, and men's sexual strategy (e.g., having a young, fertile mate) would be more important to men's status than women's status; we found support for small but reliable sex differences across all these domains, except for resource acquisition ability (see Figure 8).

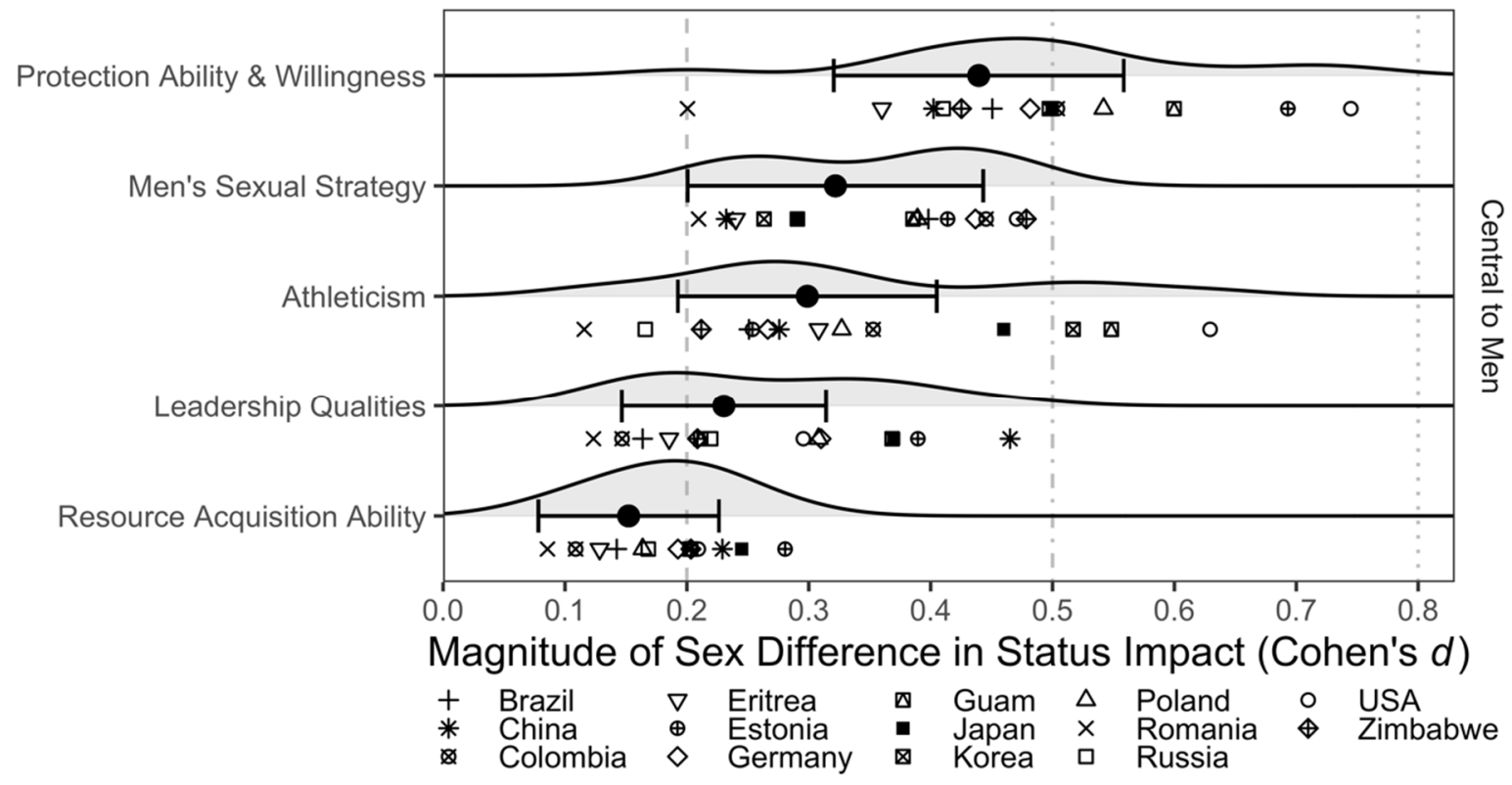

Figure 8. Meta-analyzed sex differences within domain clusters that were hypothesized to be more central men's status than women's status. Dotted lines represent conventional effect size cutoffs. Error bars represent $95 \%$ confidence intervals. 
Content level. Analysis at the content level revealed additional interesting nuances (see Figure 9). The overall sex difference of men's sexual strategy on status appears to be driven by medium-sized sex differences in having younger mates, which has a negative association with women's status, but a positive association with men's status. Additionally, although the overall domain of resource acquisition ability is not sex-differentiated, closer examination at the content level revealed that hunting ability increases men's status more than it does women's.

The domain of leadership also warrants further examination. Leadership qualities appear more central to men's than women's status at the domain level, but the influence content-cluster increases women's status about as much as it increases men's status. The difference at the domain level appears to be driven by conformity, which lowers men's status more than women's, and holding a leadership position, which increases men's status more than women's (see Figure 9). 


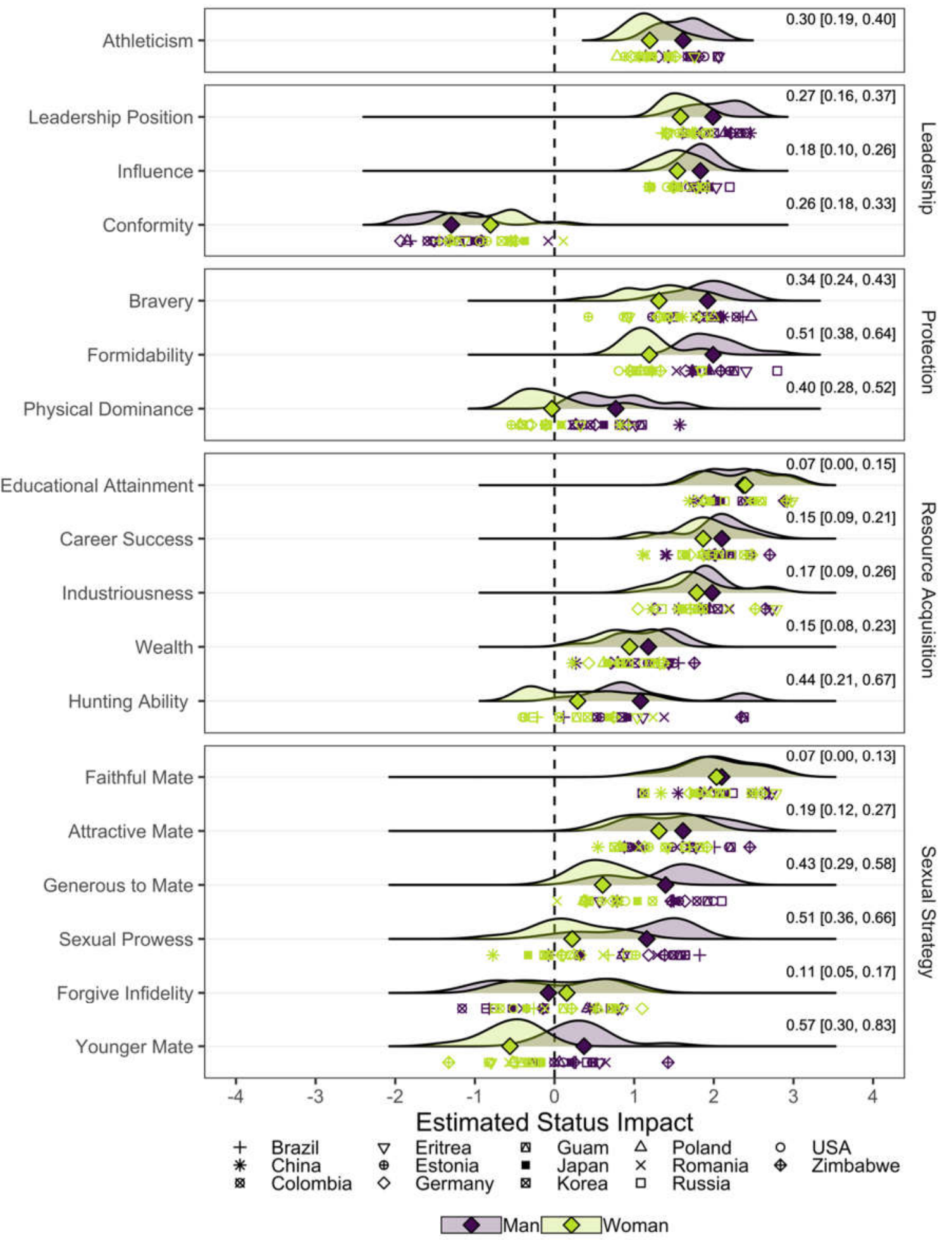

Figure 9. Plot of status criteria central to men, depicting the average relative status impacts on men and women as well as the absolute magnitude of the sex difference (Cohen's $d$ and 95\% confidence intervals). 


\section{Status Criteria More Central to Women}

Domain level. We found support for the domain-level predictions that domestic skills, attractiveness, and aspects of women's sexual strategy (e.g., chastity/purity) would be more central to women's status than men's status (see Figure 10).

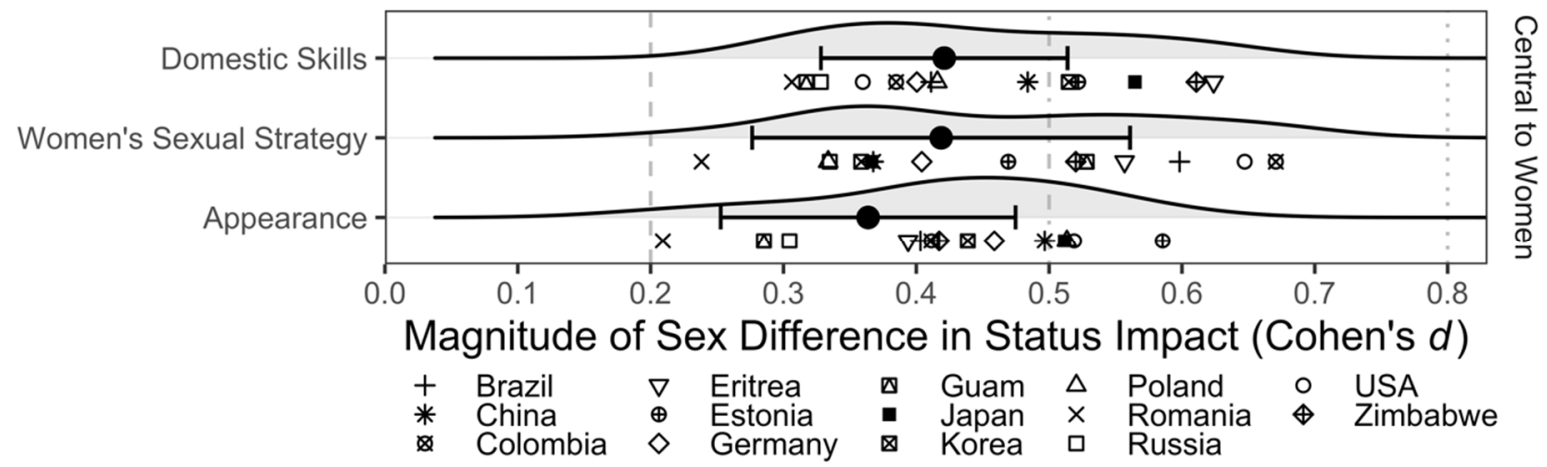

Figure 10. Meta-analyzed sex differences within domain clusters that were hypothesized to be more central women's status than men's. Dotted lines represent conventional effect size cutoffs.

Content level. As shown in Figure 11 the content-level analyses further confirmed that all components of attractiveness (i.e., hygiene, appearance) and domestic skills (i.e., cooking ability, parenting skill, and cleanliness) are more central to women's status than men's status across the countries sampled. Sex differences in the effects of women's sexual strategy on status are especially clear at the content level. Infidelity, chastity/purity, and long-term mating success increase women's status more than men's. Sexual promiscuity lowers the status of both sexes, but lowers it more dramatically for women than for men (see Figure 11). 


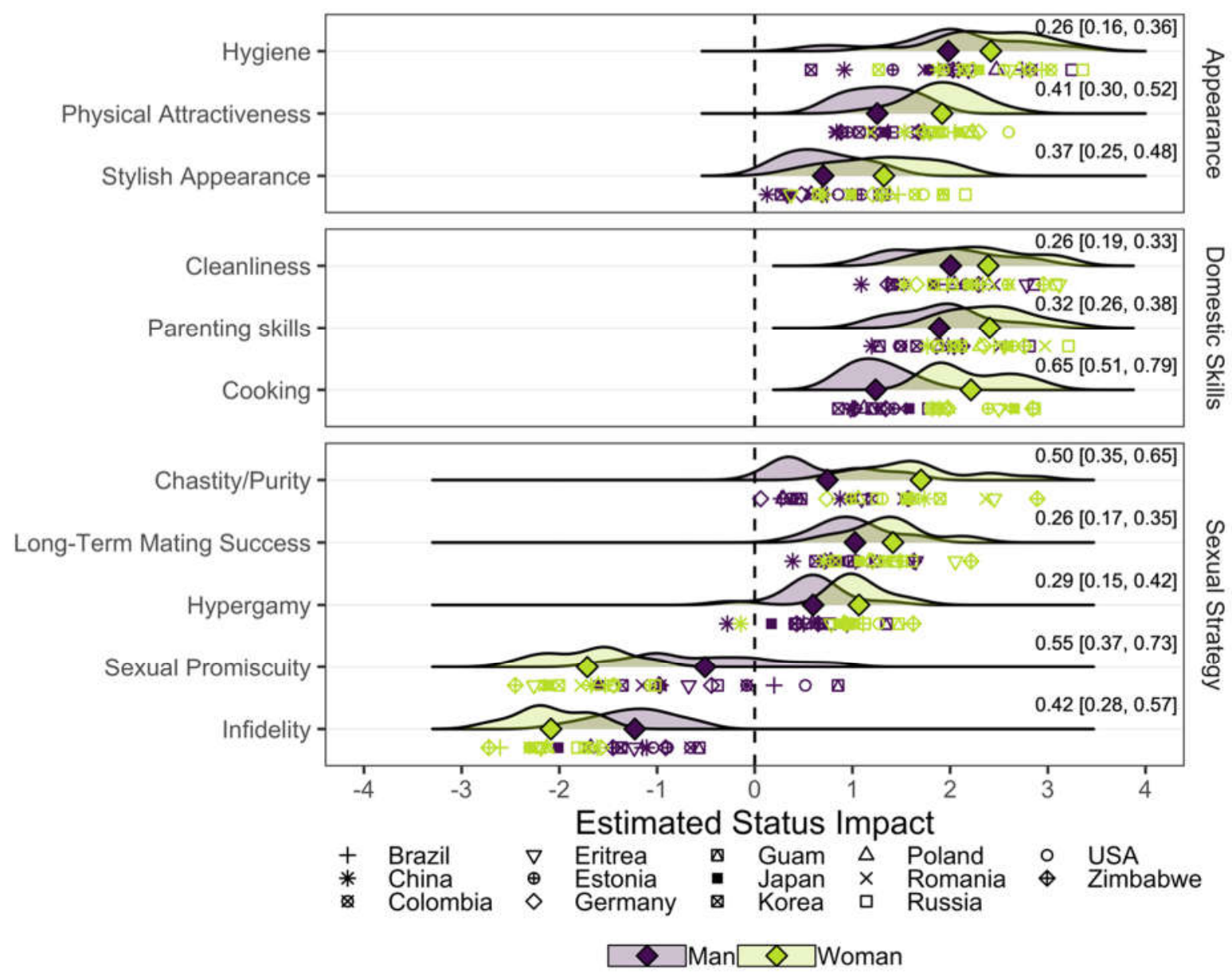

Figure 11. Plot of status criteria central to women, organized by domain-cluster, depicting the average relative status impacts on men and women as well as the absolute magnitude of the sex difference (Cohen's $d$ and 95\% confidence intervals).

Some additional item-level findings are noteworthy. The overall sex difference in hypergamy that favors women seems to be driven by item-level differences in (a) "having a spouse who is more intelligent than oneself" $(d=0.56 ; 95 \%$ CI $[0.35,0.77])$ and (b) "having a spouse who earns more money than oneself" $(d=0.84 ; 95 \%$ CI $[0.64,1.04])$ which both raise women's status, but lower men's status. Additionally, securing a wealthy mate is equally beneficial for the status of both men and women at the content level, but item-level analyses suggest that women's status is more damaged than men's by marrying someone who is poor $(d=$ $-0.25 ; 95 \%$ CI $[-0.32,-0.17])$. At the item level, being a virgin is harmful to men's status but 
beneficial to women's status $(d=0.81 ; 95 \%$ CI $[0.64,0.98])$, and losing one's virginity before marriage is detrimental to women's status but has essentially no effect on men's $(d=-0.78 ; 95 \%$ CI $[-0.93,-0.62]$; see Supplemental Materials, Section 1.2, Figure 3). Finally, the sex difference in the impact of long-term mating success appears to be driven by the larger decrease in status that women experience upon failing to secure a mate, or after being divorced-items that address simply finding a long-term mate tend to be equally beneficial to the status of both men and women (see Supplemental Materials, Section 1.2, Figure 3).

\section{Exploratory Analyses}

Finally, we explored the impacts of content-clusters and items about which we did not make a priori predictions. As shown in Figure 12, some interesting sex differences exist at the level of content clusters that were not predicted. First, drug use and delinquency seems to harm men's status much less than women's. These differences are even more pronounced at the item level; for example, "being able to drink more alcohol than one's peers” increases men's status slightly but decreases women's status severely $(d=-0.76 ; 95 \%$ CI $[-0.87,-0.62]$; see Supplemental Materials, Section 1.4, Figure 2). Second, at the content-level, most of the effects of personality are not sex-differentiated, but there does appear to be a small bias in extraversion that favors men (see Figure 12). 


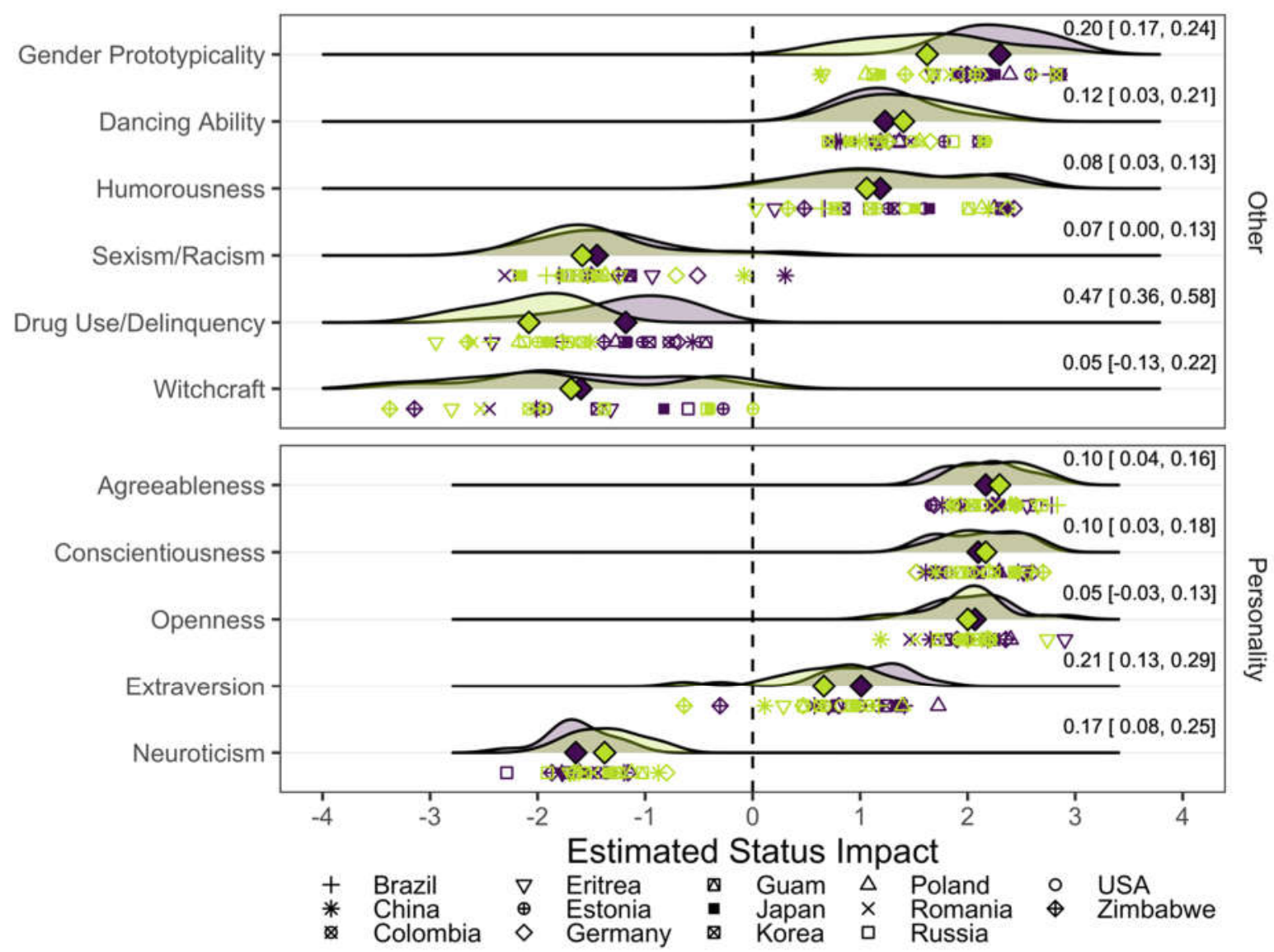

$\checkmark$ Man $\diamond$ Woman

Figure 12. Plot of exploratory status criteria depicting the average relative status impacts on men and women as well as the absolute magnitude of the sex difference (Cohen's $d$ and 95\% confidence intervals).

For the most part, these exploratory effects do not appreciably differ at the item-level, but there are some notable exceptions. First, "crying in front of one's friends" is much more damaging to men's status than women's $(d=0.63 ; 95 \%$ CI $[0.50,0.77]$; see Supplemental Materials, Section 1.4, Figure 5). Second, the sex difference in the effect of genderprototypically on status is trivial at the content-level of analysis, but the items within that cluster - "acting masculine" and "acting feminine" - are the most sex-differentiated items in our data, with respective Cohen's $d$ values of -1.80 (95\% CI $[-2.12,-1.48])$ and 2.20 (95\% CI [1.96, 
2.45]. Acting masculine lowers women's status but raises men's; and acting feminine lowers men's status but raises women's (Supplemental Materials, Section 1.4, Figure 3).

\section{Results summary}

An overview of our meta-analytic results at the domain level according to our hypotheses is shown in Figure 13. The domain-level results largely support our hypotheses: we found only trivial sex differences in domains that were hypothesized to be equally important to both men and women. We also found sex differences in all but one of domains that were hypothesized to be sex-differentiated. The sole exception centered on resource acquisition ability, for which there was a sex difference in the predicted direction, but with a trivial effect size, mostly driven by the effect of hunting skills. 

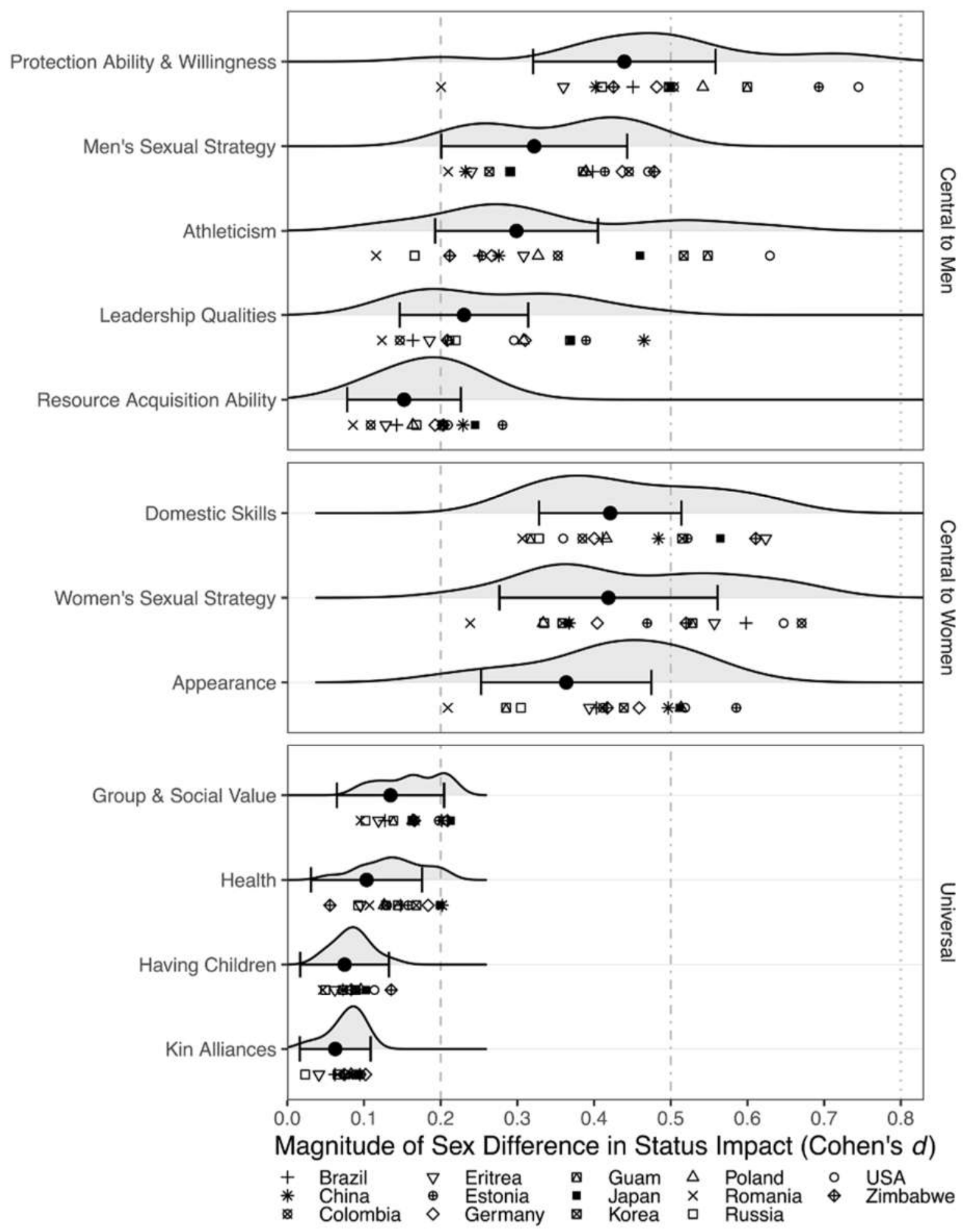

Figure 13. Overall meta-analyzed sex differences for each domain, grouped according to our hypotheses. Dotted lines represent common Cohen's $d$ effect-size cutoffs. Error bars represent $95 \%$ confidence intervals. 


\section{Discussion}

This 14-nation study provides the first systematic examination of (1) the detailed criteria used by humans to assess and allocate status and (2) the impacts that specific acts, characteristics, and events have on the status of men and women. Drawing on evolutionary metatheory, we hypothesized that human status criteria reflect numerous and specific evolved preferences, values, and expectations across the full range of evolutionarily recurrent relationships, such as mating relationships, coalitional relationships, familial relationships, and social exchange partnerships. We therefore expected the criteria by which men and women are evaluated to be similar across many domains, and that sex differences in status criteria would exist in domains where components of relationship value differed for men and women across our evolutionary history. Data from 14 countries on the status-impacts of a multitude of acts, characteristics, and events provide preliminary support for our theory of human status criteria.

\section{Status Criteria Shared by Men and Women}

At the core of human status criteria is a set of traits that would have been valuable in both men and women across the ancestral social landscape. Being healthy, having strong kin alliances, and embodying characteristics generally valuable across relationship domains — such as trustworthiness, willingness to share resources with others, and having a wide range of knowledge - are central to the status of both men and women among their peers. These qualities render both men and women valuable as mates, as dyadic allies, as kin members, and as coalition members - and apparently do so for men and women equally.

The only non-trivial sex difference we observed across the set of content clusters that we predicted to be the same for men and women was "retaliating after an insult"; results showed that this act is not as beneficial to women's status as men's. In hindsight, this difference makes sense 
on Nisbett's (1993) theory of the role of violence in honor. He hypothesized that men who failed to respond with strong retaliation after public insult would suffer large blows to their status, particularly among men living in ecological conditions in which reputation for retaliation deterred other men from encroaching on critical and purloinable resources. Future work could test predictions from this hypothesis by studying the status impacts of retaliation in cultures that vary in these ecological conditions, such as contrasting herding cultures with agrarian cultures, cultures with weak versus strong systems of law enforcement, and so on. Aside from this sole sex difference that we failed to predict a priori, the numerous status criteria that are not sexdifferentiated reflect the broad array of adaptive problems and components of social value largely shared by men and women.

\section{Sex-Differentiated Status Criteria}

We now turn to domains in which we hypothesized that adaptive challenges and components of social value would have differed somewhat for men and women across our evolutionary history, therefore leading to sex-differentiated status criteria. Consistent with our hypotheses, women's status differentially hinged on both physical attractiveness and domestic skills. Although our results show that physical attractiveness is important to the status of both men and women, physical attractiveness had a greater effect on women's status, in accordance with the hypothesis that ancestral women's value across relationships would have been somewhat more dependent on physical attractiveness than that of men's. In contrast, men's status centered on specific components of coalitional value, such as athleticism, bravery, physical formidability, and aspects of leadership, which by hypothesis was relatively less central to ancestral women's relationship value. 
We also predicted that men's status would be more dependent on wealth, industriousness, education, and career success than women's because ancestral men's value across relationship domains would have been at least partially dependent on resource acquisition abilities; however, we found no sex differences in these domains, with the sole exception of hunting skills. The reason for this is not immediately clear, as it is well established that economic resources are more central to men's than to women's mate value - a finding robust across several large-scale cross-cultural studies (Buss, 1989; Buss \& Schmitt, 2019; Walter et al., 2020). Perhaps our reasoning about this domain was flawed and we should not have expected sex differences across such a broad array of resource acquisition abilities. After all, any person who could reliably access resources would be valuable across many domains - regardless of their sex. Considering these findings, this hypothesis should be revised to expect sex differences only in the specific types of resource acquisition that would have made a larger impact on the value of ancestral men than women, such as the robust sex difference in the impact of hunting ability. Alternatively, it is possible that resource acquisition abilities, broadly construed, have a more significant impact on the relative status of men and women in real-world situations involving mate selection than would be suggested by subjects' responses to the items in our study. Future research will need to test this revised hypothesis more explicitly.

Sexual strategies and status. We found support for the prediction that sexual strategies are associated with status for both men and women. Aspects of men's sexual strategy, such as securing short-term mating opportunities, being generous to potential mates, and attracting young, fertile mates were indeed more central to men's status than women's status. Contrary to predictions, we did not find sex differences in the status impacts of having a faithful mate or forgiving infidelity; both were predicted to affect men's status more than women's status based 
on the stronger selection pressures that cuckoldry has exerted on men's fitness. The impacts of sexual strategy on women's status, in contrast, center on criteria reflecting chastity, purity, fidelity, and lack of promiscuity. These differences in the impacts of sexual strategy on the status of men and women closely mirror the sex-specific criteria that are desired in potential mates (Buss \& Schmitt, 2019). Men and women who embodied these criteria could have used their resulting status to further their preferred sexual strategies, which likely upregulates self-esteem and further increases ability to pursue preferred sexual strategies (Schmitt \& Jonason, 2019).

Masculinity and femininity. The large sex differences in the impacts of acting masculine and feminine found in our exploratory analyses deserve further consideration for three reasons - because they were not predicted by our model, because they appear to have profound status consequences, and because they show the largest sex-differentiated status consequences in the entire 14-nation study. Prior research has found that masculine traits include assertive, forceful, has leadership abilities, is willing to take risks, dominant, and has a strong personality, and feminine traits include affectionate, sympathetic, sensitive to the needs of others, understanding, compassionate, warm, tender, and gentle (Gaudreau, 1977). Other research has found that both masculine and feminine traits can have positive group-beneficial qualities as well as negative group-harmful qualities. For example, the negative aspects of masculinity (unmitigated agency) include making decisions without consulting others involved in them, ridiculing someone in the presence of the group, and instructing others to perform menial tasks rather than doing them oneself (Buss, 1990). Negative aspects of femininity (unmitigated communion) include walking out of a store knowing one has been short-changed without saying anything, tolerating an insult without retorting, and "Agreeing that I was wrong even though I wasn't” (Buss, 1990). It appears that participants' folk concepts track more closely the positive 
aspects of masculinity and femininity than the negative aspects because both are associated with higher sex-specific status.

\section{Theoretical Implications and Future directions}

Taken together, these findings offer evidence that manifest human status criteria reflect evolved mechanisms designed to assess and order conspecifics according to sex-specific fitness affordances. Manifest status is a combination of all the numerous acts, characteristics, and events that we have examined here, and undoubtedly many that we have not examined. The sex differences in status criteria, ranging from small to medium in effect size, have substantial practical and theoretical implications that offer many potential directions for future study across psychological research.

Evolutionary implications. The differences in the impacts of a given attribute or ability for men and women quickly compound. Over human evolutionary history, these small effects would have had profound fitness consequences. For example, men who achieved high status by virtue of their value as a coalition member and as a potential mate would have been preferentially sought out by desirable coalitions and desirable mates — something known to occur in many cultures, for example among Ache men who attain status from their hunting skills (Hill \& Hurtado, 1996). Similarly, women who achieved high status by virtue of their value in different relationships or alliances would have been preferentially sought, would have obtained more valuable mates, and would have possessed social capital beneficial to kin and offspring. Over evolutionary time, these differences would have created and sustained selection pressures that further maintained the patterns of behavior, values, attitudes, thoughts, feelings, and cultural norms and status criteria present in modern human cultures. 
Of course, we are not denying that culture can either amplify or diminish the magnitude of such sex differences through socialization. Nor are we denying that various cultures provide distinct kinds of opportunities for the development and expression of these sex differences. However, by positing that these sex differences are rooted in evolutionary processes can we explain the fact that such differences appear to be culturally universal. The available evidence suggests that these phenomena cannot be explained solely in terms of the arbitrary social creation and enforcement norms and values imposed by one dominant group. Whatever our attitudes may be toward such norms and values, evolutionary biological analyses are crucial to a full understanding of their origins.

Mismatches between ancestral and modern environments. There exist known mismatches between ancestral and modern environments (Li, van Vugt, \& Colarelli, 2018). The underlying mechanisms that evaluate social value and drive status criteria, therefore, do not necessarily reflect reliable differences in social value in the modern world.

For example, physical formidability may have been critical to ancestral male coalitions that required feats of strength and psychological bravery to prevail in small-group warfare or large-game hunting. The fact that we found that these qualities continue to contribute to men's status may reflect one such mismatch in the modern environment; aside from delimited athletic contests, there is no evidence that physical formidability directly contributes to the success of coalitions in business settings, university settings, or among teams of computer programmers. On the other hand, formidability and bravery may continue to be relevant social assets in protecting kin, mates, and friends from physical assault or sexual assault, for example as implied by the “bodyguard hypothesis" (Wilson \& Mesnick, 1997). Future research is needed to identify which 
status criteria continue to contribute to social value and which are archaic vestiges of adaptive problems no longer relevant in modern environments.

Another interesting direction would be to study whether and how certain behaviors that were status-enhancing in our ancestral past are now maladaptive. For example, men's participation in violent coalitional contests may have been adaptive in the ancestral past as way to display bravery and physical prowess, and ultimately increase their status — selecting for motivations in young men to pursue those activities. In many modern cultures, these motivations might lead young men to engage in activities that have negative social consequences, no longer increase status, reduce the chances of attracting a mate, or are otherwise detrimental to fitness. For instance, the growing body of research suggesting that the disproportionate amount of time young men invest in violent multi-player video games lowers their physical fitness, economic prospects, and attractiveness to women (e.g., Dorn, \& Hanson, 2019) provides some evidence of a potential mismatch between evolved status criteria and the modern world.

Levels of abstraction. The current conceptual framework and limited empirical research partially elides a key issue: levels of abstraction in status criteria. Looking across cultures, one culture might value hunting ability, another a medical degree, and a third entrepreneurial achievement. At a higher level of abstraction, however, these seemingly diverse status criteria may simply embody traits or skills relevant to the generation or acquisition of socially valued benefits within a specific cultural context. Similarly, those in Canada might esteem hockey ability, those in Europe soccer skill, and indigenous Amazonians success in chest-pounding duals (Chagnon, 1968); but at a higher level of abstraction, all are components of athletic prowess or formidability. 
What appears at lower-order levels to be culturally variable status criteria may in fact be universal status criteria at a higher level of abstraction. Deciding the appropriate level of abstraction will therefore be critical in accurately understanding cultural variability in status criteria. Future theoretical and empirical work will need to address this complicated, and perhaps only somewhat tractable, issue of mapping culturally specific status criteria at the correct level of abstraction.

Conceptualizations of status. There are several conceptualizations of hierarchical rank in the literature. For example, theoretical distinctions are made between power, rank, dominancebased status, prestige-based status, reputational regard, and status broadly conceptualized; these distinctions are actively debated (Cheng et al., 2013; Jiminez \& Mesoudi, 2019; Galinsky, Rucker, \& Magee, 2015; Lukaszewski et al., 2016). In this preliminary investigation, we adopted a relatively broad conceptualization of status as a component of hierarchical rank based on respect and reputational regard. Interesting differences in the centrality of certain criteria may arise using alternative conceptualizations of status. A critical direction for future research will be to empirically examine differences in the weight given to different criteria under different theoretical conceptualizations. Such investigations may help to distinguish empirically between overlapping status constructs and address definitional issues.

Perspectival shifts in status criteria. Status criteria exist "in the eyes of the beholder," or perhaps more precisely "in the adaptations of the beholder." Just as individuals' value changes depending on who they are being evaluated by and the purpose for which the evaluation is made, so too should the criteria used to allocate and assess status. Therefore, status criteria should predictably shift according to characteristics of the individual doing the evaluating, such as their age, their relationship to the referent, their own physical characteristics and abilities, and their 
own status. Family members, for instance, might place greater weight on a woman's fertility and reproductive success when evaluating her status than will a potential same-sex friend who is evaluating her as a reciprocal exchange partner because reproductive potential is more closely tied to kin value than to a reciprocal exchange partner. Similarly, a man's coalitional allies may place greater weight on his bravery and willingness to take risks for the group than does his mate for whom those risks may imperil the survivorship of her partner and co-parent.

Ecological shifts. Future research should examine ecological shifts in status criteria, where ecology includes both the physical and cultural environment. Different physical and cultural environments select for different skills and traits to be valued; status criteria should shift accordingly. In environments with high parasite loads, for instance, attractiveness, health, and caretaking skills may be especially valued and should consequently be weighted more heavily in status assessments. Likewise, hunting ability should be weighted more heavily in environments in which large-game, cooperative hunting is common or in which hunting returns are extremely variable than in environments characterized by small-game hunting, fishing, or greater dependence on horticulture.

Other important ecological factors will need to be examined, such as (i) extant sex ratio, which could lead to status criteria being more important for the sex that is overrepresented in the mating market; (ii) gender egalitarianism of the culture under investigation, which could reduce sex differences in status criteria for some domains, such as domestic skills; and (iii) history of warfare, which might influence the weight placed on characteristics relevant to men's coalition value in assessing status. A critical future direction will be to explicitly examine the ecological variables that predict shifts in specific status criteria, which will require a larger and more diverse sampling from cultures than we secured for this initial investigation. 
Although our 14-nation study covers a diverse range of countries and cultures, there are many interesting and diverse populations that remain understudied (Gurven, 2018). Future research should sample even more countries and cultures to afford a more holistic assessment of the nuances in status criteria across ecologies and cultures. For example, comparisons could be made between broad cultural characteristics, such as individualistic and collectivistic cultures (Triandis, 1996), WEIRD-ness (Henrich, Heine, \& Norenzayan, 2010), and between dignity and honor cultures (Leung \& Cohen, 2011), as well as more comparisons of status criteria between racial groups within countries and between rural and non-rural populations.

The ontogeny of status criteria. Status criteria undoubtedly have sex-typical ontogeny curves. Adolescents males, for example, are generally regarded as lower in status than mature males - at least by women seeking long-term mates. Adolescent females, in contrast, accrue status in many cultures for their value as potential mates (Symons, 1979). The status accorded to older people varies across cultures, depending on their culture-specific value to kin and coalitions. In cultures in which older people command valuable political resources or valuable information, such as among the Tiwi of northern Australia (Hart \& Pilling, 1960), they would be predicted to be highly valued.

The status ontogeny curves for men and women are also predicted to be different, in part because of age differences in the components of sex-differentiated social value and because of the variance linked with these components. A woman's mate value-which we have shown is central to her status - is highly influenced by her reproductive value, which declines sharply with age. A man's mate value, on the other hand, is more influenced by hunting skills, which typically peak somewhere between the mid- to late-30s (Gurven, Kaplan, \& Gutierrez, 2006; Hill \& Hurtado, 1996; Walker, Hill, Kaplan, \& McMillan, 2002). In Western societies, financial 
income peaks between the mid-30s and mid-50s. Thus, our theory predicts sex-specific ontogeny curves for status, with men's generally peaking later than women's. Men's resource accrual trajectories are also more variable than women's reproductive value trajectories. Consequently, chronological age should be a stronger predictor of women's status than men's status.

The ratings of status impacts in the current study were provided by relatively young samples of convenience. Consequently, our findings may generalize better to populations of similarly aged individuals than to older populations. Future research should sample a broader range of ages and examine age-related shifts in status criteria explicitly.

\section{Conclusion}

The current investigation is the first to examine the specific criteria by which humans evaluate and accord status cross-nationally. Our theoretical model suggests that human status criteria reflect a complex mixture of evolutionary, environmental, and cultural forces. Our findings highlight the myriad criteria central to both men and women, as well as those that are sex-differentiated. Future research is needed to further examine the complicated array of factors that led to the evolution and maintenance of numerous and specific human status criteria and the multitudes of adaptations that have evolved to navigate the complexities of status hierarchies. 


\section{Acknowledgements}

We are immensely grateful to the cross-national collaborators who provided, or helped to provide, data from their respective countries: Lucio Ferreira Alves (Brazil), Alois Angleitner (Germany), Henok Araya (Eritrea), Sergey Biriucov (Russia), Mariko Hasegawa (Japan), Toshikazu Hasegawa (Japan), Carol Hodge (Guam), Stanislaw Mika (Poland), Kathleen Myambo (Zimbabwe), Toomas Niit (Ukraine), and Kaiping Peng (China). We are appreciative of the editor and three anonymous reviewers for their critical feedback, who helped to improve the quality of this paper. Additional thanks go to Richard Alexander, Don Brown, Michael Chen, Leda Cosmides, Courtney Crosby, Todd DeKay, Bruce Ellis, Arlette Greer, Kim Hill, Warren Holmes, Tim Ketelaar, Bobbi Low, Randy Nesse, Steve Pinker, Anna Sedlacek, Jennifer Semmelroth, Barb Smuts, Don Symons, John Tooby, and Valerie Stone for helpful critical reactions on earlier drafts of this paper. 


\section{References}

Alexander. R. (1987). The biology of moral systems. New York: Aldine de Gruyter.

Anderson, C., Hildreth, J. A. D., \& Howland, L. (2015). Is the desire for status a fundamental human motive? A review of the empirical literature. Psychological Bulletin, 141(3), 574.

Anderson, C., \& Kilduff, G. J. (2009). The pursuit of status in social groups. Current Directions in Psychological Science, 18(5), 295-298.

Apostolou, M. (2007). Sexual selection under parental choice: The role of parents in the evolution of human mating. Evolution and Human Behavior, 28(6), 403-409.

Apostolou, M. (2013). Sexual selection under parental choice: The evolution of human mating behavior. New York: Psychology Press.

Barkow, J. (1980). Prestige and self-esteem: A biosocial interpretation. In D.R. Omark, F.F. Strayer, \& D.G. Freedman (Eds.), Dominance relations: An ethological view of human conflict and social interaction. New York, NY: Garland STPM Press.

Barkow, J. H. (1989). Darwin, sex, and status: Biological approaches to mind and culture. University of Toronto Press.

Bates, D., Maechler, M., Bolker, B., \& Walker, S. (2015). 1me4: Linear mixed-effects models using Eigen and S4. R package version 1.1-7. 2014.

Benjamin, D. J., Berger, J. O., Johannesson, M., Nosek, B. A., Wagenmakers, E. J., Berk, R., ... \& Cesarini, D. (2018). Redefine statistical significance. Nature Human Behaviour, 2(1), 6.

Betzig, L. (1986). Despotism and differential reproduction: A Darwinian view of history. Hawthorne, N.Y.: Aldine. 
Blader, S. L., \& Chen, Y. R. (2014). What's in a name? Status, power, and other forms of social hierarchy. In The psychology of social status (pp. 71-95). Springer, New York, NY.

Broude, G. J. (1990). The division of labor by sex and other gender-related variables: An exploratory study. Behavior Science Research, 24(1-4), 29-49.

Brown, P. (1990). Big Man, past and present: model, person, hero, legend. Ethnology, 29(2), 97115.

Bush, J. M., Quinn, M. M., Balreira, E. C., \& Johnson, M. A. (2016). How do lizards determine dominance? Applying ranking algorithms to animal social behaviour. Animal Behaviour, 118, 65-74.

Buss, D. M. (1988). The evolution of human intrasexual competition: tactics of mate attraction. Journal of personality and social psychology, 54(4), 616.

Buss, D. M. (1989). Sex differences in human mate preferences: Evolutionary hypotheses tested in 37 cultures. Behavioral and brain sciences, 12(1), 1-14.

Buss, D. M. (1989b). Conflict between the sexes: Strategic interference and the evocation of anger and upset. Journal of personality and social psychology, 56(5), 735.

Buss, D. M. (1990). Unmitigated agency and unmitigated communion: An analysis of the negative components of masculinity and femininity. Sex Roles, 22(9-10), 555-568.

Buss, D. M. (1991). Evolutionary personality psychology. Annual review of psychology, 42(1), 459-491.

Buss, D.M. (1994/2016). The evolution of desire: Strategies of human mating. New York: Basic Books.

Buss, D. M. (1995). Psychological sex differences: Origins through sexual selection. American Psychologist, 50, 164-168. 
Buss, D. M., \& Schmitt, D. P. (1993). Sexual strategies theory: an evolutionary perspective on human mating. Psychological review, 100(2), 204.

Buss, D. M., \& Schmitt, D. P. (2019). Mate preferences and their behavioral manifestations. Annual review of psychology, 70, 77-110.

Chagnon, N. (1968). Yanomamo social organization and warfare. War: The anthropology of armed conflict and aggression, 109-159.

Chagnon, N. (1983). Yanomamo: The fierce people, 3rd edition. New York: Holt, Rinehart, \& Winston.

Chapais, B. (2015). Competence and the evolutionary origins of status and power in humans. Human Nature, 26(2), 161-183.

Chase, I. D., \& Seitz, K. (2011). Self-structuring properties of dominance hierarchies: a new perspective. In Advances in genetics (Vol. 75, pp. 51-81). Academic Press.

Cheng, J. T., Tracy, J. L., Foulsham, T., Kingstone, A., \& Henrich, J. (2013). Two ways to the top: Evidence that dominance and prestige are distinct yet viable avenues to social rank and influence. Journal of Personality and Social Psychology, 104(1), 103-125.

Cosmides, L., \& Tooby, J. (2015). Adaptations for reasoning about social exchange. In D.M. Buss (Ed.) The handbook of evolutionary psychology (2 ${ }^{\text {nd }}$ ed.) (pp. 625-668). Hoboken, NJ: Wiley.

Dorn, D., \& Hanson, G. (2019). When Work Disappears: Manufacturing Decline and the Falling Marriage Market Value of Young Men. American Economic Review: Insights, 1(2), 16178. 
DeVore, I., \& Tooby, J. (1987). The reconstruction of hominid behavioral evolution through strategic modeling. The Evolution of Human Behavior: Primate Models, edited by WG Kinzey, 183-237.

Frank. R.H. (1985). Choosing the right pond: Human behavior and the quest for status. New York: Oxford University Press.

Galinsky, A. D., Rucker, D. D., \& Magee, J. C. (2015). Power: Past findings, present considerations, and future directions.

Garfield, Z. H., Hubbard, R. L., \& Hagen, E. H. (2019). Evolutionary Models of Leadership: Tests and Synthesis. Human nature (Hawthorne, NY).

Gaudreau, P. (1977). Factor analysis of the Bem Sex-Role Inventory. Journal of Consulting and Clinical Psychology, 45(2), 299-302.

Gregg, A., Sedikides, C., \& Pegler, A. (2018). Self-esteem and social status: Dominance theory and hierometer theory. Encyclopedia of evolutionary psychological science. Berlin: Springer International Publishing AG. doi, 10, 978-3.

Gurven, M. D. (2018). Broadening horizons: Sample diversity and socioecological theory are essential to the future of psychological science. Proceedings of the National Academy of Sciences, 115(45), 11420-11427.

Gurven, M., Kaplan, H., \& Gutierrez, M. (2006). How long does it take to become a proficient hunter? Implications for the evolution of extended development and long life span. Journal of human evolution, 51(5), 454-470.

Gurven, M., \& Von Rueden, C. (2006). Hunting, social status and biological fitness. Social biology, 53(1-2), 81-99. 
Hart, C.W.M., \& Pilling, A.R. (1960). The Tiwi of North Australia. New York: Holt, Rinehart, and Winston.

Hawkes, K., \& Jones, N. B. (1991). Hunting income patterns among the Hadza: big game, common goods, foraging goals and the evolution of the human diet. Phil. Trans. R. Soc. Lond. B, 334(1270), 243-251.

Hawley, P. H. (1999). The ontogenesis of social dominance: A strategy-based evolutionary perspective. Developmental Review, 19(1), 97-132.

Henrich, J., \& Gil-White, F. J. (2001). The evolution of prestige: Freely conferred deference as a mechanism for enhancing the benefits of cultural transmission. Evolution and human behavior, 22(3), 165-196.

Henrich, J., Heine, S. J., \& Norenzayan, A. (2010). Most people are not WEIRD. Nature, 466(7302), 29.

Hill, K. (1982). Hunting and human evolution. Journal of Human Evolution, 11(6), 521-544.

Hill, K., \& Hurtado, A. M. (1996). Ache life history: The ecology and demography of a foraging people. Routledge.

Holekamp, K. E., \& Strauss, E. D. (2016). Aggression and dominance: an interdisciplinary overview. Current Opinion in Behavioral Sciences, 12, 44-51.

Hrdy, S. B. (2009). The woman that never evolved. Harvard University Press.

Kaplan, H., Gurven, M., Hill, K., \& Hurtado, A. M. (2005). The natural history of human food sharing and cooperation: a review and a new multi-individual approach to the negotiation of norms. Moral sentiments and material interests: The foundations of cooperation in economic life, 6, 75-113. 
Kaplan, H., \& Hill, K. (1985). Hunting ability and reproductive success among male Ache foragers: Preliminary results. Current anthropology, 26(1), 131-133.

Kirkpatrick, L.A., \& Ellis, B.J. (2001). An evolutionary approach to self-esteem: Multiple domains and multiple functions. In G. Fletcher \& M. Clark (Eds.), The Blackwell handbook of social psychology (Vol. 2, pp. 411-436). Oxford, U.K.: Blackwell.

Kraus, M. W., Piff, P. K., \& Keltner, D. (2011). Social class as culture: The convergence of resources and rank in the social realm. Current Directions in Psychological Science, 20(4), 246-250.

Kyl-Heku, L. M., \& Buss, D. M. (1996). Tactics as units of analysis in personality psychology: An illustration using tactics of hierarchy negotiation. Personality and Individual Differences, 21(4), 497-517.

Leung, A. K. Y., \& Cohen, D. (2011). Within-and between-culture variation: individual differences and the cultural logics of honor, face, and dignity cultures. Journal of personality and social psychology, 100(3), 507.

Li, N. P., van Vugt, M., \& Colarelli, S. M. (2018). The evolutionary mismatch hypothesis: Implications for psychological science. Current Directions in Psychological Science, 27(1), 38-44.

Liebenberg, L. (2008). The relevance of persistence hunting to human evolution. Journal of Human Evolution, 55(6), 1156-1159.

Lukaszewski, A. W., Simmons, Z. L., Anderson, C., \& Roney, J. R. (2016). The role of physical formidability in human social status allocation. Journal of Personality and Social Psychology, 110(3), 385. 
Lund, O. C. H., Tamnes, C. K., Moestue, C., Buss, D. M., \& Vollrath, M. (2007). Tactics of hierarchy negotiation. Journal of Research in Personality, 41(1), 25-44.

Magee, J.C., \& Galinsky, A.D. (2008). Social hierarchy: The self-reinforcing nature of power and status. Academy of Management Annals, 2, 351-398.

Mahadevan, N., Gregg, A. P., \& Sedikides, C. (2018). Is self-regard a sociometer or a hierometer? Self-esteem tracks status and inclusion, narcissism tracks status. Journal of personality and social psychology.

Manson, J. H., Wrangham, R. W., Boone, J. L., Chapais, B., Dunbar, R. I. M., Ember, C. R., ... \& Paterson, J. D. (1991). Intergroup aggression in chimpanzees and humans [and comments and replies]. Current anthropology, 32(4), 369-390.

Morris, S. B., \& DeShon, R. P. (2002). Combining effect size estimates in meta-analysis with repeated measures and independent-groups designs. Psychological methods, 7(1), 105.

Nisbett, R. E. (1993). Violence and US regional culture. American psychologist, 48(4), 441.

Pandit, S. A., Pradhan, G. R., Balashov, H., \& Van Schaik, C. P. (2016). The conditions favoring between-community raiding in chimpanzees, bonobos, and human foragers. Human Nature, 27(2), 141-159.

Patton, J. Q. (2005). Meat sharing for coalitional support. Evolution and human behavior, 26(2), $137-157$.

Piddocke, S. (1969). The potlatch system of the southern Kwakiutl: a new perspective. In Environment and cultural behaviour: ecological studies in cultural anthropology (pp. 130-156).

Price, M. E. (2003). Pro-community altruism and social status in a Shuar village. Human Nature, 14(2), 191-208. 
Ridgeway, C. L., \& Walker, H. A. (1995). Status structures. In S. Cook, G. A. Fine, \& J. H. House (Eds.), Sociological perspectives on social psychology (pp. 281-310). Boston, MA: Allyn \& Bacon

Schmitt, D. P., \& Jonason, P. K. (2019). Self-esteem as an adaptive sociometer of mating success: Evaluating evidence of sex-specific psychological design across 10 world regions. Personality and Individual Differences, 143, 13-20.

Shostak, M. (1981). Nisa: The life and words of a !Kung woman. Cambridge, MA: Harvard University Press.

Stanford, C. B. (1999). The hunting apes: Meat eating and the origins of human behavior. Princeton University Press.

Stibbard-Hawkes, D. N. (2019). Costly signaling and the handicap principle in hunter-gatherer research: A critical review. Evolutionary Anthropology, 1-14. https://doi.org/10.1002/evan.21767

Sugiyama, L. (2015). Physical attractiveness: an adaptationist perspective. In D. M. Buss (Ed.), The handbook of evolutionary psychology (pp. 317-384). Hoboken, NJ: Wiley.

Symons, D. (1979). The evolution of human sexuality. New York: Oxford University Press.

Symons, D. (1987). If we're all Darwinians, what's the fuss about? In C. Crawford, M. Smith, \& D. Krebs (Eds.), Sociobiology and psychology (pp. 121-46). Hillsdale, NJ: Erlbaum.

Tooby, J., \& Cosmides, L. (1988). The evolution of war and its cognitive foundations. Institute for evolutionary studies technical report, 88(1), 1-15.

Tooby, J. \& Cosmides, L. (1989). The innate versus the manifest: How universal does universal have to be? Behavioral and Brain Sciences, 12, 36-37. 
Tooby, J., \& Cosmides, L. (1990). The past explains the present: Emotional adaptations and the structure of ancestral environments. Ethology and sociobiology, 11(4-5), 375-424.

Tooby, J., \& Cosmides, L. (2010). Groups in mind: The coalitional roots of war and morality. Human morality and sociality: Evolutionary and comparative perspectives, 91-234.

Triandis, H. C. (1996). The psychological measurement of cultural syndromes. American psychologist, 51(4), 407.

Trivers, R. (1972). Parental investment and sexual selection. (Vol. 136, p. 179). Cambridge, MA: Biological Laboratories, Harvard University.

van Vugt, M., Cremer, D. D., \& Janssen, D. P. (2007). Gender differences in cooperation and competition: The male-warrior hypothesis. Psychological science, 18(1), 19-23.

van Vugt, M., \& Tybur, J. M. (2015). The evolutionary foundations of hierarchy: Status, dominance, prestige, and leadership. In D. M. Buss (Ed.), The handbook of evolutionary psychology (2nd ed.). Hoboken, NJ: Wiley.

von Rueden, C. R., \& Jaeggi, A. V. (2016). Men's status and reproductive success in 33 nonindustrial societies: Effects of subsistence, marriage system, and reproductive strategy. Proceedings of the National Academy of Sciences, 113(39), 10824-10829.

Walker, R., Hill, K., Kaplan, H., \& McMillan, G. (2002). Age-dependency in hunting ability among the Ache of Eastern Paraguay. Journal of Human Evolution, 42(6), 639-657.

Walter, K. V., Conroy-Beam, D., Buss, D. M., Asao, K., Sorokowska, A., Sorokowski, P., ... \& Amjad, N. (2020). Sex Differences in Mate Preferences Across 45 Countries: A LargeScale Replication. Psychological Science, 0956797620904154. 
Willer, R. (2009). A status theory of collective action. In Altruism and prosocial behavior in groups (pp. 133-163). Emerald Group Publishing Limited.

Wilson, M., \& Mesnick, S. L. (1997). An empirical test of the bodyguard hypothesis. In Feminism and evolutionary biology (pp. 505-511). Springer, Boston, MA. 